\title{
Do US Anglers Care about Harmful Algal Blooms? \\ A discrete choice experiment of Lake Erie recreational anglers
}

\author{
Wendong Zhang and Brent Sohngen \\ Working Paper 17-WP 573 (revised) \\ February 2018 \\ Center for Agricultural and Rural Development \\ lowa State University \\ Ames, lowa 50011-1070 \\ www.card.iastate.edu
}

Wendong Zhang is assistant professor in the Department of Economics, lowa State University, Ames, lowa. E-mail: wdzhang@iastate.edu

Brent Sohngen is a professor in the Department of Agricultural, Environmental and Development Economics, The Ohio State University, Columbus, Ohio. E-mail: sohngen.1@osu.edu.

This publication is available online on the CARD website: www.card.iastate.edu. Permission is granted to reproduce this information with appropriate attribution to the author and the Center for Agricultural and Rural Development, lowa State University, Ames, lowa 50011-1070.

Acknowledgements: The authors gratefully acknowledge the support from Lake Erie Commission and the NOAA/Ohio Sea Grant Program.

For questions or comments about the contents of this paper, please contact Wendong Zhang, wdzhang@iastate.edu. 


\title{
Do US anglers care about harmful algal blooms?
}

\section{A discrete choice experiment of Lake Erie recreational anglers}

\begin{abstract}
Despite the growing awareness of harmful algal blooms (HABs) in the US and abroad, estimates of welfare losses due to their presence are missing from the literature. Using a mail survey of 767 Ohio Lake Erie recreational angler respondents and a choice experiment, this study provides the first empirical quantification of the economic impacts of HABs on US recreational anglers. Our results demonstrate a significant and substantial willingness to pay by anglers for reduction in HABs, beyond the benefits associated with conventional water quality measures such as catch rates and water clarity. For instance, we find that anglers are willing to pay \$8-\$10 more per trip for one less mile of boating through HABs enroute to a fishing site. This finding suggests that explicit measures of HABs need to be collected and considered when valuing water quality in nutrient-rich waterbodies. We evaluate the welfare improvements resulting from several nutrient reduction policies, and find that anglers are willing to pay on average $\$ 40-60$ per trip for a policy that cuts upstream phosphorus loadings by $40 \%$.The majority of welfare gains for anglers result from improving the non-catchable component of the fishing experience, notably water clarity and HAB reduction, as opposed to better chances of angler success. Keywords: Choice experiment, discrete choice, generalized multinomial logit model, harmful algal bloom, Lake Erie, non-market valuation, recreational angler, recreation demand, survey, water quality

JEL Codes: Q51, Q53, Q57, Q15
\end{abstract}


Over the past few decades, there has been an increasing incidence and extent of freshwater eutrophication and coastal hypoxia in the United States and across the globe (Diaz and Rosenberg, 2008), including the Great Lakes region, the Gulf of Mexico, the Baltic Sea in Europe, and Lake Taihu in China. Although more than 300 algal species may cause the blooms, only one-third of them are deemed toxic algae, and thus aptly termed as a "harmful algal bloom” (HAB) (Hudnell 2010). Cyanobacteria, especially those sub-species that could produce toxins such as microcystis, are of particular concern. In 2011, the western basin of Lake Erie experienced a cyanobacteria blue-green algae growth of unprecedented size and severity (Michalak, et al., 2013). A 2015 bloom was ever larger and more severe (Stumpf et al. 2016). The HABs in Lake Erie are also often accompanied by a significant and ever-growing hypoxic zone—a zone of low or no dissolved oxygen, which is often greater than $4,000 \mathrm{~km}^{2}$ in the summer months (Scavia et al. 2017). The primary cause of the HAB and hypoxia in Lake Erie and the Great Lakes region is the excessive inputs of nitrogen and phosphorus, mainly due to crop and livestock production in upstream agricultural watersheds (Michalak et al. 2013). As a result, the State of Ohio developed a statewide nutrient reduction strategy in 2013 that targets a $40 \%$ reduction in total phosphorus as well as spring total and dissolved reactive phosphorus (DRP) entering Lake Erie from upstream watersheds in the western Lake Erie basin (Ohio EPA 2013).

These cyanobacteria HABs have severely compromised multiple ecosystem services provided by Lake Erie, including recreation opportunities, public health, and safe 
drinking water. A prime example is that in 2014, the algal toxins in Lake Erie disrupted the water services in the City of Toledo, resulting in millions of residents left without safe drinking water for two or more days (Raymond 2015). Ohio EPA estimated that approximately \$3 billion per year is being incurred to deal with algal toxins in Ohio public water systems (Raymond 2015; US EPA 2015; Westrick et al. 2010). In addition, these toxic cyanobacteria such as microcystis pose public health risks to human and animals $^{\mathrm{i}}$ : in 2010 alone, were 10 suspect illness cases in Lake Erie (Ohio.gov 2016), and a cyanobacteria-produced liver-toxin, microcystin, was also detected in the fish from Lake Erie (Wituszynski et al. 2016), leading to advisories of consuming only one fish per week from Lake Erie due to concern about HABs. Dubbed the Walleye Capital of the World, Lake Erie is home to a $\$ 1.5$ billion sport fishing industry for over two million anglers, and has what is considered world class walleye and small bass fisheries (Lucente et al. 2012). It also boasts a host of recreational destinations that offer beach-going, fishing, and boating, and has $\$ 3.5$ billion in residential housing stock within half mile of the Lake Erie shoreline (Bingham, Sinha, and Lupi 2015). Scientific studies have shown that HABs can lead to fish kills, thereby posing a threat to the fishery industry through the creation of hypoxic conditions (Diaz and Rosenberg, 2008, Rucinski, et al., 2010). However, HABs are also odorous and unpleasant, even if they do not directly affect fish catch rates (Hudnell 2010).

A large literature has been devoted to the economic valuation of benefits resulting from water quality improvements, using both revealed preference and stated preference 
methods (Egan et al. 2009; Fenichel, Abbott, and Huang 2013; Hynes, Tinch, and Hanley 2013; Kosenius 2010: Phaneuf and Smith 2005; Van Houtven et al. 2014; Viscusi, Huber, and Bell 2008; Whitehead et al. 2010). More specifically, numerous studies have examined the willingness to pay for fishing trips and for changes in fishing site characteristics in the Great Lakes region (Bogue 2001; Lupi, Hoehn, and Christie 2003; Melstrom and Lupi 2013; Provencher and Bishop 1997) as well as for Lake Erie in particular (Hushak, Winslow, and Dutta 1988; Kelch et al. 2006). However, none of these studies evaluate welfare losses from HABs; rather, they valued changes in catch rate or water clarity improvements.

Two recent unpublished reports are suggestive that the number of fishing trips to Lake Erie is declining in recent years due to rising level of algal toxin levels (Weicksel and Lupi, 2013; Bingham, Sinha, and Lupi 2015); however, these descriptive reports rely on yearly aggregate summary statistics and back-of-the-envelope calculations. Wolf et al (2017) find that fewer people purchase licenses during HAB outbreaks, but they do not value the effect of HABs on trips or the fishing experience. Recently, Palm-Forster et al. (2016) estimated the welfare losses from simulated HAB-induced Lake Erie beach closures using benefit transfer, but did not collect primary data or actually model changes in HABs. Kosenius (2010) used a choice experiment to examine willingness to pay of the Finnish public for nutrient reductions in the Baltic Sea, but it focused on the general public rather than recreational users directly impacted by HABs. In sum, there lacks a 
clear identification of economic impacts of HABs beyond conventional water quality improvements such as catch rates and water clarity.

There are three objectives of this study: (1) to assess Lake Erie recreational anglers' willingness to pay for water quality improvements; (2) for the first time, to discern whether there is an economic impact of HABs on US anglers, and (3) to quantify the magnitude of that impact on Lake Erie’s sport fishing industry. We hypothesize that Lake Erie recreational anglers have a considerable willingness to pay for a reduction in HABs in Lake Erie. Previous studies have shown that recreational anglers differ in preferred species and fishing success, as well as non-catchable components of the fishing experience (see for example, Bergstrom and Cordell 1991; Rosenberger and Loomis 2001; Melstrom and Lupi 2013), which result from heterogeneous underlying preferences across recreational anglers. Because HABs are a relatively recent phenomena, and their impacts vary across space and time (both within and across years), the possibility of a bloom can introduce additional uncertainty in the fishing experience and potentially amplify the preference heterogeneity ${ }^{\text {ii }}$. For example, recent trawl surveys reveal that the hypoxic zone could induce concentration of fish populations near the edge of hypoxia, resulting in new spatial variations in catch rates (Kraus et al. 2015). We investigate these anglers' heterogeneous preferences through a mail survey of 767 Ohio recreational angler respondents in 2014. To assess preferences, we employ a choice experiment with varying water quality characteristics at Lake Erie fishing sites. Specifically, respondents were asked to choose their favorite hypothetical fishing site, characterized not only by 
conventional water quality attributes such as walleye catch rates and water clarity, but also a new measure of HAB intensity-miles of HABs the anglers have to boat through before reaching their preferred fishing destination.

Using multiple discrete choice models, we estimate anglers’ demands for a reduction in the size and intensity of HABs, as well as conventional water quality betterment such as improved water clarity and increases in walleye catch rates. The models we estimate are a conditional logit model (CL), a random parameters logit model (RPL), a latent class model (LCM), a scaled multinomial logit (SNL), as well as a generalized multinomial logit (G-MNL) model that combines the features of RPL and SNL. We also estimated RPL models with correlated random parameters. One common problem of the traditional CL model is that it assumes fixed preference parameters for all anglers and thus has restrictive substitution patterns due to its Irrelevance of Independent Alternative (IIA) assumption. RPL, LCM, SNL, and G-MNL relax this assumption, and are used to assess heterogeneity in preferences among Ohio recreational anglers for HAB reduction and other water quality improvements. We estimate multiple alternatives to the CL model as robustness checks.

We expect substantial variations in the anglers' underlying preferences for fishing success and water quality attributes. The anglers could have fundamentally varying taste in a host of issues such as which fish species to target, whether to fish in the shoreline or from a boat, as well as caring only about fishing success or about the impact of HABs on 
the fishing and boating experience as a whole. This heterogeneity could result in differences in household's awareness, knowledge and past experience of HABs in Lake Erie (Stumpf et al. 2016). This could also result from the individual constraint that anglers' choices are based on, such as income, time availability, health status such as skin allergy to algae, and boat ownership (Phaneuf 2013). The ever-growing HABs in Lake Erie amplifies the underlying preference heterogeneity, and could impact not only the pleasure of trip enroute to and at the specific fishing site, but also affect the ability to catch fish, especially through the ecological response of fish population to HAB-induced hypoxia (Kraus et al. 2015). The models we estimate differ in how they introduce the heterogeneity. The RPL and LCM models account for unobserved taste heterogeneity by allowing for continuous or discrete random coefficients for observed variables, while SNL allows for scale heterogeneity, which captures the randomness of the decision making process via a general scaling up or down of the entire vector of attribute weights (Keane and Wasi 2013). G-MNL has features from both RPL and SNL, but allows for greater correlation among coefficients in a more general functional form (Fiebig et al. 2010). G-MNL could also be viewed as a special case of RPL with fully correlated random parameters (Hess and Train 2017).

We find substantial willingness to pay for water quality improvements in Lake Erie, regardless of model specification: Typical anglers are willing to pay $\$ 8-\$ 10$ per trip for one less mile of $\mathrm{HAB}$ through which they need to boat before reaching the desired fishing site, \$37-\$51 per trip for one less hour needed to catch one more walleye, and \$65-\$96 
per trip for an improvement in water clarity from murkier conditions to clear. While there is a wide range of values for water quality improvements among the respondents, the average willingness to pay is robust and stable across all models. We focus our welfare analysis on the two G-MNL models with normal and lognormal mixing because they account for various forms of heterogeneity and they allow for correlation among coefficients through the scale parameter. Allowing for correlation is important, we argue, because HABs have little effect on catch rates (the traditional measure of welfare) while strongly affecting other measures of fishing experience or cost. While the G-MNL-II with normal mixing has better goodness-of-fit and out-of-sample forecast accuracy in our application, the G-MNL-II with lognormal mixing has theoretically consistent signs and thus welfare measures. Using an integrated model that couples our recreational demand model with a three-dimensional lake hydrodynamic-lower food web model, we evaluate the welfare improvements from three nutrient reduction policies that managed to reduce total and dissolved phosphorus from the western Lake Erie basin by 10\%, 20\%, and 40\%, respectively. Our results find that Ohio recreational anglers are willing to pay $\$ 40-\$ 60$ per trip for a policy that would cut DRP by $40 \%$. The estimates represent a $16 \%-24 \%$ loss over the aggregate consumer surplus for Ohioans angling in Lake Erie if we assume $10 \%$ of trips to Lake Erie were affected by HABs in a normal year. In addition, we show that the welfare gains from these policies are mainly from improvements that could enhance the non-catchable components of the fishing experience, namely water clarity and reduction in $\mathrm{HAB}$ size, as opposed to increases in catch rates. 
This article makes several contributions to the literature of non-market valuation of ecosystem services. First, this is the first study to demonstrate that harmful algal blooms, a growing environmental concern in the United States and abroad, lower recreational anglers' welfare. Second, we showcase the recreational anglers' willingness to pay for HABs reduction above and beyond the conventional water quality measures, suggesting that limiting water quality measures to traditional ones, such as water clarity or catch rates, could lead to an underestimate of welfare improvements. This also suggests that more research is needed to distinguish what are the most salient measures of water quality in recreational demands to account for emerging issues like HABs. Third, our welfare analysis based on an integrated ecological-economic model suggests that the economic improvements of nutrient reductions are mainly manifested through the noncatchable component of the fishing experience rather than changes in walleye catch rates. Finally, while our models reveal evidence of heterogeneous preferences, our results are remarkably robust across specifications, yielding mean WTP for water quality improvements that are quite similar. This finding is encouraging for welfare analysis and could result from stable angler preferences as well as a successful survey design ${ }^{\mathrm{iii}}$.

The remainder of the article is organized as follows: we first describe the estimation methodology, followed by the description of the data and survey design. We then present the results of the discrete choice models, which include the estimation of the welfare measures associated with various nutrient management policies. Finally, we discuss some of the implications of the models and conclude. 


\section{Methodology}

\section{Discrete Choice Models}

The Random Utility Maximization (RUM) model has become the standard statistical economic framework in models of recreational demand (McFadden 1974, Freeman Herriges and Kling 2014). In a choice experiment setting, respondents are asked to choose among alternative recreational destinations or policy options that are characterized by various attributes. The RUM model posits that an individual chooses the alternative that yields the highest expected utility among a number of alternatives on any given choice occasion. Assume that recreational angler $i$ has $J$ possible multiattribute fishing sites from which to choose in the choice experiment setting; the utility $U_{i j t}$ that angler $i$ derives from alternative $j$ in choice situation $t$ is given by

$$
\text { (1) } \quad U_{i j t}=V_{i j t}+\varepsilon_{i j t} \text {, }
$$

where $V_{i j t}$ is the observable indirect utility from visiting fishing site $j$, and $\varepsilon_{i j t}$ is the error term which captures the unobserved, stochastic element of the utility. The conditional logit model (CL) has been the most widely used discrete choice model in recreation demand studies. With a CL model, utility can be represented by

$$
U_{i j t}=\beta^{\prime} \mathrm{X}_{\mathrm{ijt}}+\varepsilon_{i j t}
$$


Here, $X_{\mathrm{ijt}}$ is a vector of perceived site attributes including travel cost, and $\beta$ is the corresponding coefficients for these attributes, while the error term $\varepsilon_{i j t}$ is independently and identically drawn from a type-I extreme value distribution.

As shown in equation (2), CL assumes the equality of the utility functions across the respondents, and thus results in homogenous taste parameter estimates. However, previous studies have shown heterogeneity is a defining feature of nonmarket valuation (Phaneuf 2013), due to both multiple observed and unobserved factors driving recreation demand and heterogeneous individual characteristics and preferences. In addition, the estimation of only average preferences, as in CL—or misspecification of the taste distribution more generally—may lead to biased welfare analysis and incorrect representation of the value of recreation sites with particular attributes that appeal to a subset of the population (Train 2009, Fiebig et al. 2010).

In recent years, discrete choice modelers have accounted for the unobserved heterogeneity in tastes and preferences with several additional approaches. However, there is no single alternative that is viewed as superior to all other alternatives. Currently, the two most popular approaches in empirical applications are random parameters logit (RPL) model and latent class model (LCM). Both of these models allow for individual preference variations, thereby relaxing the IIA property. These approaches, however, have differing distributional assumptions. RPL allows for individual-specific, random 
coefficients on observed attributes and assumes a continuous distribution for individuals' preferences:

$$
U_{i j t}=\beta_{i}{ }^{\prime} \mathrm{X}_{\mathrm{ijt}}+\varepsilon_{i j t}=\left(\beta+\eta_{i}\right)^{\prime} \mathrm{X}_{\mathrm{ijt}}+\varepsilon_{i j t} .
$$

As shown in equation (3), $\beta$ is the vector of mean attribute utility weights in the population, while $\eta_{i}$ is the angler $i$ 's specific deviation from the mean. Theoretically, the mixing distribution for $\beta_{i}$ in the RPL model can be anything, but it is commonly specified as multivariate normal. LCM, on the other hand, models the parameter heterogeneity across individuals with a discrete distribution which is a function of individual characteristics. The respondents are grouped into a few ( $\mathrm{K}$ as in equation (4)) “discrete” segments or classes that remain latent for the researcher. Within each class k, the preferences are homogenous (Greene and Hensher 2003):

$$
U_{i j t}=\beta_{k}{ }^{\prime} \mathbf{X}_{\mathrm{ijt}}+\varepsilon_{i j t} \quad i \epsilon k, \quad k=1,2 . . K
$$

Most recently, several researchers such as Louviere, Hensher, and Swait (2000) argue that the taste heterogeneity in most choice contexts can be better described as "scale" heterogeneity—meaning that for some anglers, the scale of the idiosyncratic error term is greater than for others. To better understand what scale heterogeneity means, rewrite the simple CL model in equation (1) with the scale of the error term, $\sigma$, made explicit instead of being normalized to one:

$$
\text { (2a) } \quad U_{i j t}=\beta^{\prime} \mathrm{X}_{\mathrm{ijt}}+\varepsilon_{i j t} / \sigma \text {. }
$$


The scale heterogeneity logit (S-MNL) model assumes that $\sigma$ is heterogeneous in the population and hence denotes the value for angler $i$ by the scalar random variable $\sigma_{i}$, we thus obtain:

$$
U_{i j t}=\beta^{\prime} \mathrm{X}_{\mathrm{ijt}}+\varepsilon_{i j t} / \sigma_{i} .
$$

In (5a), all heterogeneity is in the variance of the error term while the $\beta$ vector is homogenous. However, heterogeneity in scale is observationally equivalent to a certain type of heterogeneity in utility weights (Keane and Wasi 2013). Multiply (5a) by the random scale variable $\sigma_{i}$ we obtain equation (5b), which can be interpreted as a RPL model with $\beta_{i}=\sigma_{i} * \beta$. As a result, heterogeneity in S-MNL takes the form of the vector of utility weights and $\beta$ is scaled up or down proportionally across the respondents by the scaling factor $\sigma_{i}$.

$$
U_{i j t}=\beta_{i}^{\prime} \mathrm{X}_{\mathrm{ijt}}+\varepsilon_{i j t}=\left(\sigma_{i} * \beta\right)^{\prime} \mathrm{X}_{\mathrm{ijt}}+\varepsilon_{i j t}
$$

While the S-MNL provides an alternative way of introducing preference heterogeneity compared to RPL with normal mixing or LCM, the scaling factor $\sigma_{i}$ in SMNL has to be positive for all individuals and is commonly assumed to follow an exponential distribution. As a result, the vector of random coefficients $\beta_{i}$ for all respondents must have the same sign, which is not imposed in the RPL model. If we assume generally positive valuation for improvements in water quality attributes, S-MNL could avoid negative WTPs imposed by RPL with normal mixing. Depending on whether the coefficient for the price is adjusted by the scaling factor or not, S-MNL could have SMNL with and without price or travel cost scaled. More recently, efforts have been made 
to develop a model that nest S-MNL and RPL with normal or lognormal mixing.

Specifically, Fiebig et al. (2010) developed a model called the generalized multinomial logit (G-MNL) model, which models the heterogeneity distribution as a continuous mixture of scaled normal or even lognormal. The normal mixing RPL and S-MNL are both special cases of G-MNL model (Keane and Wasi 2013). The general form of GMNL model is given by

$$
U_{i j t}=\beta_{i}{ }^{\prime} \mathrm{X}_{\mathrm{ijt}}+\varepsilon_{i j t}=\left[\sigma_{i} \beta+\gamma \eta_{i}+(1-\gamma) \sigma_{i} \eta_{i}\right]^{\prime} \mathrm{X}_{\mathrm{ijt}}+\varepsilon_{i j t}
$$

where the parameter $\gamma$ determines how the standard deviation of the random coefficients is scaled: in particular, when $\gamma=0$, we obtain a model called G-MNL-II in which the standard deviations of the random coefficients $\eta_{i}$ are scaled proportionally to their mean attribute weights. In this study, we employ this specific model, G-MNL-II, which starts with normal mixing RPL and multiplies through $\sigma_{i}$ :

$$
U_{i j t}=\beta_{i}{ }^{\prime} \mathrm{X}_{\mathrm{ijt}}+\varepsilon_{i j t}=\left[\sigma_{i}\left(\beta+\eta_{i}\right)\right]^{\prime} \mathrm{X}_{\mathrm{ijt}}+\varepsilon_{i j t}
$$

It is important to note that the RPL models can be estimated with correlated random parameters and this particular G-MNL-II model can be viewed as a restricted form (Hess and Train 2017) $)^{\text {iv }}$.

In the choice experiment setting, each individual $i$ makes a sequence of T choices. The unconditional probability of an angler $i$ choosing site $\mathrm{j}$ in the sequence of choice scenarios can be represented by

$$
P_{i j}=\int \prod_{t=1}^{T} L_{t}\left(j \mid \beta_{i}\right) f(b, \Omega) d \beta_{i}
$$




$$
=\int \prod_{t=1}^{T} \frac{\mathrm{e}^{V_{i j t}}}{\sum_{j=1}^{J} \mathrm{e}^{V_{i j t}}} f(b, \Omega) d \beta_{i}=\int \prod_{t=1}^{T} \frac{\mathrm{e}^{\beta_{i}{ }^{\prime} \mathrm{x}_{\mathrm{ijt}}}}{\sum_{j=1}^{J} \mathrm{e}^{\beta_{i}{ }^{\prime} \mathrm{x}_{\mathrm{ijt}}}} f(b, \Omega) d \beta_{i} .
$$

In this formulation, $L_{t}\left(j \mid \beta_{i}\right)$ is the familiar logit probability that captures the conditional probability of choosing site $\mathrm{j}$ in choice scenario $\mathrm{t}$, and $f(\beta, \Omega)$ is the density distribution with mean $b$ and variance-covariance matrix parameters $\Omega$ to be estimated from the data. $V_{i j t}$ denotes the observed utility of choosing site $\mathrm{j}$ in choice scenario $\mathrm{t}$, and the last equality follows from the standard assumption of the utility being linear in attributes. The density $f(\beta, \Omega)$ can be specified to be discrete as in LCM or continuous in $\beta$ as in any other aforementioned models.

Welfare Analysis using models integrated with a three-dimensional coupled lake hydrodynamic - lower food web model

For the welfare analysis, we integrate the RUM model with a dynamically coupled lake hydrodynamic lower food web model known as ELCOM-CAEDYM specifically calibrated for Lake Erie (Zhao et al. 2009; Fraker et al. 2015), which could simulate the changes in water quality attributes resulting from changes in the discharge of nutrients from Maumee, with a focus on the occurrence and extent of HABs. In particular, the hydrodynamic Estuary and Lake COmputer Model (ELCOM) (Hodges et al. 2006) is designed for spatially explicit, three-dimensional numerical simulation of hydrodynamics and thermodynamics of stratified inland and coastal waters, including water current and temperature patterns. It is dynamically coupled with the Computational Aquatic Ecosystem DYnamics (CAEDYM) (Hipsey 2008) to simulate the water and sediment 
chemical and biological processes, such as nutrient cycling, growth of various phytoplankton and zooplankton species including cyanobacteria, and sediment resuspension. ELCOM and CAEDYM together are able to generate spatially explicit (2x2 $\mathrm{km}$ scale) simulations of temporal variation in such lake characteristics as oxygen concentration, secchi depth, nutrient concentrations (e.g., N, P), algal production (e.g. cyanobacteria), and zooplankton production including fish population ${ }^{\mathrm{v}}$ (Fraker et al. 2015). In short, the coupled ELCOM-CAEDYM model simulates attribute changes from $\mathrm{X}_{i}^{0}$ to $\mathrm{X}_{i}^{1}$, and it has been applied to Lake Erie to investigate nutrient and phytoplankton dynamics (e.g. Leon et al., 2011) and hypoxic conditions (Bocaniov and Scavia 2016).

For CL, RPL, S-MNL and G-MNL, the welfare changes for individual $i$ from an attribute change from $\mathrm{X}_{i}^{0}$ to $\mathrm{X}_{i}^{1}$ and conditional on individual taste $\beta_{i}$, measured by compensating variation (CV), follows the standard utility difference expression (Hanemann 1991):

$$
\begin{gathered}
C V_{i}=-\frac{1}{\widehat{\beta_{l p}}}\left[\ln \left(\sum e^{V_{i}^{1}}\right)-\ln \left(\sum e^{V_{i}^{0}}\right)\right]=-\frac{1}{\widehat{\beta_{l p}}}\left[\ln \left(\sum e^{{\widehat{\beta_{l}}}^{\prime} X_{i}^{1}}\right)-\right. \\
\left.\ln \left(\sum e^{{\widehat{\beta_{l}}}^{\prime} X_{i}^{0}}\right)\right]
\end{gathered}
$$

where $\widehat{\beta_{l p}}$ is the parameter estimate of travel cost, $\widehat{\beta_{l}}$ is the vector of estimated random parameters for angler $i$, while $V_{i}^{1}$ and $V_{i}^{0}$ are the utility evaluated in the policy case and in the business-as-usual case, respectively. This CV measure can be interpreted as the average welfare change per choice occasion, in which each angler chooses to fish or not and which site to go. Since the fishing trips are realized choice occasions, the CV 
measure could be interpreted as per-trip WTP if we don’t consider those choice occasions for which the anglers choose to stay home. The parameter vector $\widehat{\beta}_{\iota}$ is uniform across individuals for the CL model, and varies across individuals for RPL, S-MNL, and GMNL-II models and should be calculated following equations (3), (5b), and (7), respectively. For example, $\widehat{\beta}_{\iota}=\widehat{\sigma}_{\imath} * \hat{\beta}$ for S-MNL. For RPL, S-MNL and G-MNL models, the compensating variation measures have to be approximated by simulation from draws of the estimated distributions for the random parameters (see Train 2009 for simulation methods). For LCM with K classes, the welfare measures have to be weighted by the predicted class membership probabilities:

$$
\begin{array}{r}
C V_{i}=\sum_{k=1}^{K} \widehat{\pi_{l k}}\left\{-\frac{1}{\widehat{\beta_{l p}}}\left[\ln \left(\sum e^{V_{i}^{1}}\right)-\ln \left(\sum e^{V_{i}^{0}}\right)\right]\right\} \\
=\sum_{k=1}^{K} \widehat{\pi_{l k}}\left\{-\frac{1}{\widehat{\beta_{l p}}}\left[\ln \left(\sum \widehat{e}^{\prime}{ }^{\prime} X_{i}^{1}\right)-\ln \left(\sum e^{\widehat{\beta}_{l}} X_{i}^{0}\right)\right]\right\},
\end{array}
$$

where $\widehat{\pi_{l k}}$ is the estimated posterior probability the angler $i$ of being assigned to class $k$ (Boxall and Adamowicz 2002). In this article, RPL and LCM are estimated using mixlogit (Hole 2007) and lclogit packages (Pacifico and Yoo 2012) in Stata 13, respectively, while S-MNL and G-MNL are estimated using gmnl package (Gu, Hole and Knox 2013) in Stata 13 and R (Sarrias and Daziano 2017).

\section{Data and Survey Design}

Following Dillman’s Tailored Survey Design framework (Dillman, Smyth, and Christian 2014), we conducted a general mail survey on Ohio anglers’ 2013 sport-fishing daytrips 
in spring 2014. Questionnaires were mailed to a sample of recent Ohio fishing license holders from 2011-2013 drawn from the Fishing License \& Permit Sales database of the Ohio Department of Natural Resources. The sample was screened to include only anglers that were 18 years of age or older, and those who purchased fishing licenses in the previous three years. We employed a stratified random sampling method, in which we oversample anglers from counties close to Lake Erie. Specifically, 2,500 anglers were drawn from counties alongside or close to the western or central basin of Lake Erie, while another 500 anglers were chosen from all other counties in Ohio. The number of sampled anglers from each county is proportional to the share of anglers from this county in the fishing license database.

We conducted one focus group interview with eight anglers, as well as a pilot survey with 16 separately randomly selected anglers via mail as well as online. These focus group discussions and pilot survey responses were instrumental in helping us identify key elements of the choice experiment, especially the measure of the extent of HABs. In particular, these early participants were presented with several alternative measures of HABs, such as the number of HAB occurrences over a typical fishing season, the probability of experiencing a HAB while fishing, and the maximum areal extent of HABs. We chose to represent the size of algal bloom as the distance of an algal bloom that the angler would need to boat through (from the shoreline) to get to the fishing site because, according to our focus group and pilot survey respondents, it was easier for anglers to understand and more relatable to their fishing. After all, a higher 
HAB probability or a larger maximum areal extent may not impact their individual fishing experience. A copy of the questionnaire is attached in the online supplemental appendix.

We then mailed two rounds of survey packets to these 3,000 sampled anglers in mid-January, 2014 and early-March, 2014. A final reminder card was sent out lateMarch, 2014. We broke the sample into three subsamples and employed three different modes of incentives for each subsample: for the first 1,000 anglers, a $\$ 1$ bill was included in the first round of mailings. For the other 2,000 anglers, a name card is included in the survey packet and each respondent could choose to fill the card out to enter a lottery to win Home Depot gift cards. In particular, for the second 1,000 anglers, three gift cards with $\$ 200$, $\$ 150$, and $\$ 100$ respectively were available for the lottery winners while the last 1,000 anglers could enter the lottery to win one of the six gift cards with $\$ 75$ for each. The \$1 incentive yielded a 31.8\% response rate while the gift cards led to response rates at $21 \%$ and $23.9 \%$, respectively. Figure 1 shows a map of the western Lake Erie basin, including the Maumee River watershed, which is the largest in the Great Lakes Region and contributes, by far, the largest volume of sediment and nutrient loadings into Lake Erie (Reutter et al. 2011).

We received 767 total responses, out of which 753 provided useable information for our general summary, leading to a $25 \%$ overall response rate. Of these 753,566 individuals indicated that they fished in Lake Erie in 2013, and over $80 \%$ of the 
respondents were from counties near the lake. The bulk of trips came from individuals living along or near the lake, and most trips occurred in summer and fall, with fewer trips in spring. Almost all anglers who fished in Lake Erie in 2013 are aware of algal blooms in Lake Erie, and $84 \%$ of them have recently experienced an algal bloom in recent years for 6.8 times on average (Sohngen et al. 2015). We also asked how these anglers respond to HABs with multiple options that could be selected. Fifty-three percent of them reported changing their fishing location, $16 \%$ did not go fishing, and 35\% reported to have not changed their fishing habits. HABs reduced fishing time for $34 \%$ of the anglers, but induced another $6 \%$ of respondents to spend more time fishing or target different species (Sohngen et al. 2015).

Table 1 presents the comparison of demographic and socioeconomic characteristics of anglers in our sample with the sample of Ohio resident anglers, as well as US anglers, who fished in the Great Lakes in 2011 National Survey of Fishing, Hunting and WildlifeAssociated Recreation (US Fishing and Wildlife Service and US Census Bureau 2011). Compared to the two samples from the national survey, our sample is skewed toward older anglers with higher household income and higher education, and consists of more anglers with a primary residence outside of a Metropolitan Statistical Area. As a result, we reweight the sample to be more proportional to the characteristics from the national sample when calculating aggregate welfare impacts. In addition, on average, the anglers in our sample have over 33 years of experience and one-third of them are retired. 
This study used data from a section of the survey in which respondents were presented six hypothetical choice experiment scenarios to determine individual preferences for fishing in Lake Erie. Each scenario had two alternative "hypothetical" walleye fishing sites in the lake. The sites vary in five characteristics, including the expected walleye catch rate $\left(1,2,4\right.$, and 6 hours per fish per person), ${ }^{\mathrm{vi}}$ water quality indicated by the size of algal bloom through which the anglers have to boat through to get to the fishing site $(0,4$, or 8 miles), water clarity (very murky, somewhat murky, very clear), driving distance from angler's house to their preferred boat ramps (15, 30, 45 minutes) and the boating time from the ramp to the fishing site (20, 40, 60 miles). The range of these attributes are partially based on the information from the annual reports about Ohio’s Lake Erie fisheries (ODNR 2014), as well as recent monitoring and forecasting by NOAA. In each scenario, the angler was asked to choose the walleye fishing trip that she would most prefer, with an option to choose neither of these two particular sites. We followed the D-efficient survey design principles (Ferrini and Scarpa 2007), and constructed six blocks, 72 sets of choice scenarios following the SAS Macros developed by Kuhfeld (2005). These choice scenarios were then randomly allocated to each angler. Figure 2 presents an example of the choice experiment scenario.

In the choice experiment models, we calculated the travel cost of driving from home to the nearest boat ramp, assuming the gasoline costs for driving on land are $\$ 0.52$ per mile following the Internal Revenue Service (IRS 2014). We also assume the opportunity cost of time is $33 \%$ of the wage rate (Cesario 1976), and the wage rates are 
calculated from the annual income by dividing by 2,000 hours worked per year. We examine the robustness of the results using several alternative measures of the travel cost and wage rate. In particular, we drop the portion of the vehicle depreciation from the gasoline cost and used $\$ 0.32$ per mile following suggestions by an extensive review by Huang et al. (2016), as well as alternative wage rate assumptions used by McConnell and Strand (1981). Seventy-seven percent of our angler respondents own a boat, among them $54 \%$ drive the boat to the lake while the remainder kept them at the marina, as a result we also use a higher gasoline cost, as high as $\$ 0.75$ per mile, which is similar to, or smaller, when compared to rates charged by Uber drivers in Ohio.

\section{Results}

Table 2 presents the regression results of four different discrete choice models with the pvalues for the coefficients shown in the parentheses, including CL, CL coupled with interactions with past experience about HABs and walleye chosen as the target species, G-MNL-II with normal mixing for all water quality characteristics, and a similar GMNL-II model with lognormal distribution for walleye catch rates and HAB size. We use these different distributional assumptions because ecologists have shown that there is correlation among various water quality attributes, such as higher catch rates around edges of hypoxic zone (Kraus et al. 2015) and preference of juvenile walleye for somewhat murkier water as opposed to clear water (Ludsin, DeVanna, and Smith 2014). Table 3 reports the results from a 4-class LCM, with the optimal number of classes selected based on the lowest Adjusted Bayesian Information Criterion (ABIC). Since it 
remains unclear which model is superior to other alternatives, we use multiple measures to compare and evaluate model performance. Specifically, the Akaike Information Criterion (AIC) and Bayesian Information Criterion (BIC) measures the goodness-of-fit; the likelihood dominance criterion proposed by Pollak and Wales (1991) also measures the goodness-of-fit using log-likelihood while taking into account of differences in degrees of freedom. Finally, we assess the models' out-of-sample prediction accuracy using a k-fold cross validation technique (Kohavi 1995) using crossfold package in Stata $13^{\mathrm{vii}}$, as well as the prediction accuracy for the remainder of the sample based on estimation of a $75 \%$ of the angler sample. We omit the results for RPL and SMNL because they are dominated by G-MNL-II both in terms of their ability to account for various sources of heterogeneity and correlation, and their goodness-of-fit and predictive accuracy. A comparison of model performance measures, including AIC, BIC, likelihood dominance criterion and out-of-sample prediction accuracy using k-fold cross validation, reveals that G-MNL-II and LCM outperform other models. We also estimated the RPL model with correlated random normal and lognormal parameters shown in Table A1.1 in the online supplemental appendix, which yield slightly inferior or comparable goodness of fit statistics including AIC and BIC when compared to the two G-MNL-II models shown in the main text.

We prefer these two G-MNL-II models with normal and lognormal mixing over the more widely used LCM because they account for multiple sources of preference heterogeneity and allow for correlation among water quality attributes via the scale 
parameter. G-MNL models have mainly been employed in the marketing science, health economics, or transportation studies, and less so in the non-market valuation literature. Due to its normality assumption, welfare estimates from the G-MNL-II with normal mixing can become negative, but this can be avoided by using a more theoreticallyconsistent lognormal parameter distribution instead. For this paper, we estimate both the G-MNL-II with normal mixing and with lognormal mixing.

In our results, G-MNL-II with normal mixing has better model fit and predictive accuracy, but the normality assumption results in negative welfare measures for water quality improvements and larger uncertainty for welfare measure. In contrast, the GMNL-II model with lognormal mixing avoids these negative welfare measures. but it has an insignificant scale parameter suggesting limited correlation among water quality attributes. This is problematic for our study because ecologists have showcased this correlation among various water quality attributes through their analysis of the interaction between catch rates and water clarity and hypoxic zones (Ludsin, DeVanna, and Smith 2014; Kraus et al, 2015). Further, we suspect that anglers’ preference for clearer water may not hold if water clarity improves to a level that impedes fishing success or makes no further discernable improvement in the enjoyment of the boating ride. This suggests that it is useful to account for correlation among water quality attributes, but surprisingly the scale parameter for the G-MNL-II model with lognormal mixing is insignificant. Most of our model results are fairly robust across these two G-MNL-II models and other specifications including the RPL models with correlated random parameters. 
There are several things worth noting regarding the signs and magnitudes of the estimated coefficients and standard deviations. First, the mean estimated coefficients for the travel cost and water quality attributes have the expected signs across all discrete choice models shown in table 2 . On average, Ohio anglers dislike fishing sites that are too far away and more costly. They prefer clearer water, higher walleye catch rates, and a smaller HAB size to boat through. Secondly, the models reveal substantial heterogeneity across the estimated coefficients for all four water quality attributes, confirming the importance of accounting for variations in preferences. This heterogeneity can be seen from the significant standard deviation coefficient and scale parameter in G-MNL-II, as well as the discrete classifications across Ohio recreational anglers revealed by LCM in table 3. In particular, anglers in class 1 care less about water clarity, while class 3 anglers do not value the improvements in walleye catch rates; class 2 and class 4 anglers both have balanced valuation towards water quality attributes, but class 4 anglers value water clarity more.

To better interpret the regression coefficients, we translate the regression coefficients into the marginal willingness to pay (MWTP) shown in table 4 following equation (9), which is often calculated using the ratio of estimated regression coefficient for one water quality attribute over the estimated coefficient for the travel cost. This could be interpreted as the average per-trip WTP across the six choice scenarios each angler faced in the choice experiment. While there is considerably wide distribution 
among individual anglers as evidenced by the $99^{\text {th }}$ confidence interval also presented in table 4 and the spread shown in the MWTP distribution shown in figure A1 shown in the online supplemental appendix, there is remarkable stability across the various models in the average per-trip mean WTP for the water quality characteristics. For example, across the models, Ohio anglers are on average willing to pay $\$ 8-\$ 10$ for one less mile of an algal bloom to boat through. Importantly, our results show that it is critical to include direct measures of HABs in recreational demand models of water quality beyond conventional water quality measures like water clarity and catch rates. Currently, there are ongoing debates regarding which best measures to use when modeling water quality (Kling, Keiser, and Ji 2017), our model suggests the importance of explicit and relevant measures of HABs for recreational demand involving eutrophic freshwater or marine ecosystems. Our model did also reveal considerable preference heterogeneity amongst individual anglers, despite the stable mean WTP for water quality characteristics. For example, the LCM model shows that individuals in class 4 have the largest welfare losses, and tend to be older, likely retired, and male. Given this demographic, they potentially have more experience fishing, and thus the change in environment as a result of increasing HABs causes them more harm.

We assess the stability of our model results through multiple robustness checks, including alternative model specifications, alternative gasoline cost and wage rate assumptions, as well as different ways of constructing the estimation samples. In particular, table A2 in the online supplemental appendix presents the marginal WTP for 
several versions of S-MNL and RPL models as well as the RPL models with correlated random parameters, table A4 shows the results for the G-MNL-II model for anglers located within 60 miles from Lake Erie's shore or in counties close to the shoreline only; and finally, table A4 showcases the results for models with alternative gasoline cost and wage rate parameters discussed in the previous section. These comparisons reveal that the mean WTP is stable across alternative model specifications and alternative angler samples. Finally, the robustness checks in travel cost parameters suggest that the mean WTP is more prone to changes in travel cost parameters than model specification changes $^{\text {viii }}$.

To evaluate the implications of nutrient management policies on water quality outcomes and the value anglers place on improving water quality, we develop estimates of welfare benefits for three policy scenarios based on potential reductions in dissolved phosphorus loadings from the Maumee River watershed (table 5). In particular, the three scenarios consider $10 \%, 20 \%$, and $40 \%$ reductions in the dissolved reactive phosphorus loads. The large $40 \%$ reduction is based on the recommendation of Ohio's Lake Erie Phosphorus Task Force (Ohio Lake Erie Phosphorus Task Force 2013). For each policy scenario, we evaluate the impact on HAB size, water clarity, and walleye fishing population using the aforementioned three-dimensional coupled Lake Erie hydrodynamic lower food-web model known as ELCOM-CAEDYM (Fraker et al. 2015), which could simulate the impacts of nutrient reduction on hypoxic conditions, secchi depth, algal production as well as juvenile fish population. While the ELCOM-CAEDYM could 
simulate water quality outcomes at a refined $2 \times 2 \mathrm{~km}$ spatial scale, we have to assume uniform average water quality changes because the choice experiment scenarios were not individualized. In other words, we implicitly assume that there is uniform characteristics across all Lake Erie fishing sites or there is only one fishing site in Lake Erie.

The following water quality attributes capture the current baseline condition of Lake Erie based on Ohio’s Lake Erie fisheries report and NOAA’s Lake Erie HAB bulletins: it takes roughly 2.2 hours on average to catch one walleye and three miles of $\mathrm{HAB}$ to boat through to reach the desired fishing site, and the water in Lake Erie is somewhat murky. The hydrodynamic model and a statistical model that links Maumee nutrient loadings and walleye catch rates (Ludsin, DeVanna, and Smith 2014) suggest that there would be no improvement in the walleye catch rates in the western and central basins of Lake Erie with a reduction in nutrient runoff. Recent fisheries studies also suggest that fish might over-accumulate around edges of the hypoxic zone, and thus walleye catch rates may not increase along with reduction in HABs and hypoxic zone (Kraus et al. 2015). In contrast, a reduction in phosphorus loadings would reduce HAB size and it would improve water clarity. The models suggest that improvements in water quality are nonlinear, with the $10 \%$ and $20 \%$ nutrient reductions having a small effect in comparison to the $40 \%$ reduction. We also experiment with alternative configurations of nutrient policies such as a further reduction in HAB size to only a half-mile to boat through given a $40 \%$ phosphorus reduction, and a potential corresponding $25 \%$ increase in walleye catch rates. 
Table 6 shows the distribution of per-choice-occasion compensating variation (CV) across these three nutrient management policy scenarios and three discrete choice models following equations (9) and (10), which could be interpreted as the average welfare measure per fishing trip if we don't consider those choice occasions for which anglers choose to stay home. In other words, our CV measure does not consider changes in the number of trips in response to improving water quality. Intuitively, anglers' willingness to pay for the nutrient management policies increase with the magnitude of nutrient reduction, and anglers expressed the greatest gains in CV for a change from 20\% nutrient reduction to $40 \%$ nutrient reduction. Importantly, we re-weight the samples when calculating the mean $\mathrm{CV}$ to be more aligned in age or income distribution with the national population who responded to the 2011 National Survey of Fishing and Hunting, including the Ohio resident anglers and US anglers who fished in the Great Lakes ${ }^{\text {ix }}$ (Table A5 in the online supplemental appendix). Specifically, Ohio anglers are willing to pay an average of $\$ 15-\$ 18$ per trip for a $20 \%$ reduction in spring DRP loadings from the Maumee River watershed, and more than double that amount, $\$ 40-\$ 60$ on average, for a 40\% DRP loading reduction. This is consistent with the nonlinearity of the production of ecosystem services that a larger reduction in nutrient runoff is needed to generate sizeable ecosystem services. Similarly as shown in the marginal WTP distribution, the average $\mathrm{CV}$ is robust and stable across various model specifications, suggesting that despite the significant heterogeneity across individual anglers, it may be more important and just 
sufficient for the welfare analysis if a careful survey design led to robust mean WTP measures.

Ohio Department of Natural Resources estimate that there were 762,000 fishing trips to Lake Erie in 2013 by Ohio's 1.1 million anglers, with 63\% of effort spent in the western basin and 26\% of effort in the central basin (ODNR 2014). The results from a separate travel cost analysis based on the number of actual trips taken marked on a map of Lake Erie by our respondents reveal that per-trip consumer surplus across all seasons for trips to the western basin of Lake Erie is around \$39 per trip (tables A7 and A8 in the online supplemental appendix), suggesting that the value of recreational angling to Lake Erie in Ohio is about $\$ 27.1$ million per year ${ }^{\mathrm{x}}$. In 2011, Lake Erie saw the most severe HABs in history until 2015, which led to a $25 \%-30 \%$ decrease in the number of trips and private sport fishing effort compared to the 2012 fishing season (ODNR 2013). As a result, we assume that a mild HABs would likely impact 10\% of the 762,000 fishing trips, and as discussed earlier, Ohio recreational anglers are on average willing to pay as much as $\$ 40-\$ 60$ per trip for a policy that would cut the DRP loadings from Maumee by $40 \%$. This would lead to a $\$ 4-\$ 6$ million welfare gain, which would increase annual consumer surplus of the Lake Erie sport fishing industry by $16 \%-24 \%$. This aggregate welfare measure is proportional to the number of trips affected: for example, it will double if we assume $20 \%$ of trips were impacted by HABs. We also examined the stability of this welfare measure using several robustness checks presented in tables A6 and Figure A2 in the online supplemental appendix, including assuming a further 
improvement in miles of HABs to boat through at only one-half mile given a $40 \%$ nutrient reduction, a 25\% increase in angler catch rates, as well as alternative aggregation methods and separate mean CV measures for anglers who live in nearshore counties.

We also show heterogeneity in the CV measure across individual anglers in the sample, as expected, and the CV distribution across various model specifications. Our $\mathrm{CV}$ estimates are prone to changes in assumed travel cost parameters as well as water quality changes. For instance, tables A5 and A6 in the online supplemental appendix reveal that our welfare measures would be slightly overestimated if vehicle depreciation is not included in the gasoline cost, while on the other hand, the welfare improvement would be much greater if walleye catch rates improve as a result of nutrient reduction as well. In addition, due to the presence of a subgroup of high-valuation anglers, it seems that CL or RPL with normal mixing seem to shift the normal distribution upwards to account for the extremely high coefficients for these anglers and thus often results in a higher mean MWTP. However, this is only our empirical observation and more work is needed to examine how different distributional assumptions by these models impact the distribution of CV and its impact on welfare analysis.

\section{Conclusion}

Eutrophication and HABs in freshwater and marine ecosystems are a growing public environmental concern, both in the United States and worldwide. While extensive research has shown that agricultural nutrient loadings are the primary cause, and HABs 
and other resulting water quality degradations could compromise multiple valuable ecosystem services, the previous studies fail to quantify the welfare losses from HABs on recreational demand, drinking water and related health impacts. Of particular interest, so far there is no assessment of the economic impacts of HABs on US recreational anglers, especially for the Great Lakes region. Using a mail survey of 767 Ohio Lake Erie recreational angler respondents and a discrete choice experiment, we provide the first empirical evidence in the United States to discern and quantify the economic impacts of HABs on the Great Lakes recreational anglers. Specifically, we use a discrete choice experiment in which respondents were asked to choose their favorite hypothetical fishing site, characterized not only by conventional water quality attributes such as walleye catch rates and water clarity, but also an important, novel measure of HAB intensity-miles of HABs the anglers have to boat through before reaching their preferred fishing destination. Since no single alternative is viewed superior to all others, we use multiple discrete choice models, including G-MNL, RPL and LCM, to account for heterogeneous preferences among Ohio recreational anglers.

We find significant economic benefits for Ohio recreational anglers associated with HABs reduction and other water quality improvements in Lake Erie, regardless of model specifications. Specifically, Ohio anglers are on average willing to pay as much as $\$ 8-$ $\$ 10$ for one less mile of HAB to boat through before reaching the desired fishing site. Despite significant variations in individual WTP among individual anglers, the mean WTP across multiple model specifications are fairly robust and stable. We also estimated 
the compensating variation for three different nutrient management policies that would reduce the agricultural phosphorus loadings from Maumee River watershed, the biggest tributary in the western Lake Erie basin and the largest source of nutrient impairment. On average, Ohio recreational anglers are willing to pay as much as $\$ 40-\$ 60$ for a policy that would cut the dissolved reactive phosphorus loadings from Maumee by 40\%, which would lead to a \$4-\$6 million welfare gain or $16 \%-24 \%$ increase in aggregate consumer surplus of Ohio’s angling in Lake Erie, assuming $10 \%$ of trips are affected for the over one million Ohio recreational anglers.

This article provides the first empirical evidence that links HABs and excessive agricultural pollution in the Lake Erie watershed to significant losses in ecosystem services as shown by economic damages to a multi-billion dollar revenue recreational fishing industry. We also demonstrate the importance of explicitly representing HABs in recreational demand models beyond conventional measures of water quality. Further research is needed to evaluate what the best measure is to account for HABs in these models, and our survey design suggests that it is important to use a measure that recreational demand users could relate to through its direct impacts on their visit. The welfare analysis from an integrated economic-ecological model reveals that the economic improvements of nutrient reductions are mainly manifested through improved noncatchable component of the fishing experience rather than changes in fishing success. 
There are several caveats in our welfare analysis for the nutrient reduction policies. For simplicity, we treat Lake Erie sites as one site with uniform characteristics in the welfare analysis, and future work with possible respondent interaction interfaces could ideally develop individualized scenarios based on the respondents' personal travel experiences and characteristics of their favorite sites. Our welfare measure per trip also implicitly ignored the choice occasions that did not result in fishing trips and kept the total number of trips constant, however, to the extent that improved water quality lead to more fishing trips by anglers, our welfare estimate could serve as a lower bound. Lastly, by focusing on a random sample of Ohio recreational anglers, we underestimate the economic damages to the entire Lake Erie recreational fishery due to the omission of anglers from Michigan, New York, Indiana, and Canada. 


\section{References:}

Bergstrom, J.C. and Cordell, H.K., 1991. “An analysis of the demand for and value of outdoor recreation in the United States.” Journal of Leisure Research, 23(1): 6786.

Bingham, M., S.K. Sinha, F. Lupi. 2015. “Economic benefits of reducing harmful algal blooms in Lake Erie.” Environmental Consulting \& Technology, Inc., report.

Bocaniov, S.A., L.F. Leon, Y.R. Rao, D.J. Schwab, and D. Scavia. 2016. " Simulating the effect of nutrient reduction on hypoxia in a large lake (Lake Erie, USA-Canada) with a three-dimensional lake model." Journal of Great Lakes Research 42:12281240.

Bogue, M.B. 2001. Fishing the Great Lakes: an environmental history, 1783-1933: Univ of Wisconsin Press.

Boxall, P.C., and W.L. Adamowicz. 2002. "Understanding heterogeneous preferences in random utility models: a latent class approach." Environmental and Resource Economics 23:421-446.

Cesario, F.J. 1976. "Value of time in recreation benefit studies." Land Economics 7:3241.

Diaz, R.J., and R. Rosenberg. 2008. "Spreading dead zones and consequences for marine ecosystems." Science 321:926-929.

Dillman, D., J.D. Smyth, and L.M. Christian. 2014. Internet, phone, mail and mixedmode surveys: the tailored design method, fourth ed. Wiley, New York. 
Egan, K.J., J.A. Herriges, C.L. Kling, and J.A. Downing. 2009. "Valuing water quality as a function of water quality measures." American Journal of Agricultural Economics 91:106-123.

Fenichel, E.P., J.K. Abbott, and B. Huang. 2013. "Modelling angler behaviour as a part of the management system: synthesizing a multi - disciplinary literature." Fish and Fisheries 14:137-157.

Ferrini, S., and R. Scarpa. 2007. "Designs with a priori information for nonmarket valuation with choice experiments: A Monte Carlo study." Journal of Environmental Economics and Management 53:342-363.

Fiebig, D.G., M.P. Keane, J. Louviere, and N. Wasi. 2010. "The generalized multinomial logit model: accounting for scale and coefficient heterogeneity." Marketing Science 29:393-421.

Fraker, M. E., Y. Zhao, and S. A. Ludsin. 2015. “A calibrated and validated hydrodynamic-ecological model of plankton dynamics in the western basin of Lake Erie.” Working paper, Department of Evolution, Ecology, and Organismal Biology, the Ohio State University.

Freeman, A.M., J.A. Herriges, and C.L. Kling. 2014. The measurement of environmental and resource values:theory and methods, third ed. Washington, DC: RFF Press.

Greene, W.H., and D.A. Hensher. 2003. "A latent class model for discrete choice analysis: contrasts with mixed logit.” Transportation Research Part B: Methodological 37:681-698. 
Gu, Y., A.R. Hole, and S. Knox. 2013. "Fitting the generalized multinomial logit model in Stata.” Stata Journal 13:382-397.

Hanemann, M. 1991. "Willingness to pay and willingness to accept: how much can they differ?” American Economic Review 81:635-647.

Hess, S., and K. Train. 2017. "Correlation and scale in mixed logit models” Journal of Choice Modeling 23:1-8.

Hipsey, M.R., 2008. The CWR Computational Aquatic Ecosystem Dynamics Model (CAEDYM). User Manual. Centre for Water Research (CWR), University of Western Australia.

Hodges, B., and C. Dallimore, 2006. Estuary, Lake and Coastal Ocean Model: ELCOM. Science Manual. Centre of Water Research. University of Western Australia.

Hole, A.R. 2007. "Estimating mixed logit models using maximum simulated likelihood." Stata Journal 7:388-401.

Huang, D., K. Train, D. McFadden, and K. Wise. 2016. "Is depreciation a component of marginal travel cost? A literature review and empirical analysis.” Journal of Transport Economics and Policy 50(2):1-19.

Hudnell, H.K. 2010. "The state of US freshwater harmful algal blooms assessments, policy and legislation.” Toxicon 55(5):1024-34.

Hushak, L.J., J.M. Winslow, and N. Dutta. 1988. "Economic value of Great Lakes sportfishing: the case of private-boat fishing in Ohio's Lake Erie." Transactions of the American Fisheries Society 117:363-373. 
Hynes, S., D. Tinch, and N. Hanley. 2013. "Valuing improvements to coastal waters using choice experiments: An application to revisions of the EU Bathing Waters Directive." Marine Policy 40:137-144.

Internal Revenue Service (IRS). 2014. 2014 standard mileage rates for business, medical and moving.

Keane, M., and N. Wasi. 2013. "Comparing alternative models of heterogeneity in consumer choice behavior." Journal of Applied Econometrics 28:1018-1045.

Kelch, D., F.R. Lichtkoppler, B. Sohngen, and A. Daigneault. 2006. "The value of steelhead (Onchorhynchus mykiss) angling in Lake Erie tributaries." Journal of Great Lakes Research 32:424-433.

Kling, C.L., Y. Ji, and D. Keiser. 2017. "Water-based recreation and water quality indices: a revealed preference approach.” Manuscript.

Kohavi, R. 1995. “A study of cross-validation and bootstrap for accuracy estimation and model selection.” Paper in the International Joint Conference on Artificial Intelligence (IJCAI).

Kosenius, A.-K. 2010. "Heterogeneous preferences for water quality attributes: The case of eutrophication in the Gulf of Finland, the Baltic Sea." Ecological Economics 69:528-538.

Kraus, R.T., C.T. Knight, T.M. Farmer, A.M. Gorman, P.D. Collingsworth, G.J. Warren, P.M. Kocovsky, and J.D. Conroy. 2015. "Dynamic hypoxic zones in Lake Erie compress fish habitat, altering vulnerability to fishing gears.” Canadian Journal of Fisheries and Aquatic Sciences 72:797-806. 
Kuhfeld, W.F. 2005. "Experimental design, efficiency, coding, and choice designs." In Marketing Research Methods in SAS: Experimental Design, Choice, Conjoint, and Graphical Techniques. pp. 47-97.

Leon, L.F., Smith, R.E.H., Hipsey, M.R., Bocaniov, S.A., Higgins, S.N., Hecky, R.E., Antenucci, J.P., Imberger, J.A., and S.J., Guildford, 2011. “Application of a 3D hydrodynamic-biological model for seasonal and spatial dynamics of water quality and phytoplankton in Lake Erie.” Journal of Great Lakes Research 37: $41-53$.

Louviere, J.J., D.A. Hensher, and J.D. Swait. 2000. Stated choice methods: analysis and applications: Cambridge University Press.

Lucente, J.E., T. Gabriel, G. Davis, C. Wellington, and F. Lichtkoppler. 2012. "Ohio's 2010 Lake Erie charter fishing industry." Fisheries 37:532-541.

Ludsin, S.A., K.M. DeVanna, and R.E.H. Smith. 2014. Physical-biological coupling and the challenge of understanding fish recruitment in large lakes. Canadian Journal of Fisheries and Aquatic Sciences 71:775-794.

Lupi, F., J.P. Hoehn, and G.C. Christie. 2003. "Using an economic model of recreational fishing to evaluate the benefits of sea lamprey (Petromyzon marinus) control on the St. Marys River." Journal of Great Lakes Research 29:742-754.

McConnell, K.E., and I. Strand. 1981. "Measuring the Cost of Time in Recreation Demand Analysis: An Application to Sportfishing.” American Journal of Agricultural Economics 63(1): 169-173. 
McFadden, D. (1974) "Conditional logit analysis of qualitative choice behavior." In Frontiers in Econometrics. pp. 105-142.

McFadden, D. (1974) "Conditional logit analysis of qualitative choice behavior." In Frontiers in Econometrics. pp. 105-142.

Melstrom, R.T., and F. Lupi. 2013. "Valuing recreational fishing in the Great Lakes." North American Journal of Fisheries Management 33:1184-1193.

Michalak, A.M., et al. 2013. "Record-setting algal bloom in Lake Erie caused by agricultural and meteorological trends consistent with expected future conditions." Proceedings of the National Academy of Sciences 110:6448-6452.

Ohio Environmental Protection Agency (Ohio EPA). 2013. “Public water system harmful algal bloom response strategy.” May 2013.

Ohio Department of Health, Ohio Department of Natural Resources, and Ohio Environmental Protection Agency (Ohio.gov). 2016. "State of Ohio harmful algal bloom response strategy for recreational waters.”

Ohio Department of Natural Resources (ODNR). 2013. “Ohio’s Lake Erie fisheries 2012.” Prepared by Lake Erie Fisheries Units, ODNR Division of Wildlife. Ohio Department of Natural Resources (ODNR). 2014. “Ohio’s Lake Erie fisheries 2013.” Prepared by Lake Erie Fisheries Units, ODNR Division of Wildlife. Palm-Forster, L.H., F. Lupi, and M. Chen. 2016. "Valuing Lake Erie Beaches Using Value and Function Transfers." Agricultural and Resource Economic Review 45(2): 270-292. 
Pacifico, D., and H. il Yoo (2012) "lclogit: a Stata module for estimating a mixed logit model with discrete mixing distribution via the Expectation-Maximization algorithm." In Australian School of Business Research Paper.

Phaneuf, D.J. 2013. "Heterogeneity in environmental demand." Annual Review of Resource Economics 5:227-244.

Pollak, R., and T.J. Wales. 1991. "The likelihood dominance criterion: A new approach to model selection." Journal of Econometrics 47(2):227-242.

Phaneuf, D.J., and V.K. Smith. 2005. "Recreation demand models." Handbook of Environmental Economics 2:671-761.

Provencher, B., and R.C. Bishop. 1997. "An estimable dynamic model of recreation behavior with an application to Great Lakes angling." Journal of Environmental Economics and Management 33:107-127.

Raymond, H. "Harmful algal blooms at Ohio public water systems.” Ohio EPA public water system (PWS) HAB coordinator’s presentation.

Reutter, J.M., L.E.M. Network, and S. Team. 2011. Lake Erie nutrient loading and harmful algal blooms: research findings and management implications. Ohio Sea Grant College Program, Ohio State University.

Rosenberger, R.S., and J.B. Loomis. 2001. Benefit transfer of outdoor recreation use values: A technical document supporting Forest Service strategic plan. Gen. Tech. Rep. RMRS-GTR-72. Fort Collins, CO: U.S. Department of Agriculture, Forest Service, Rocky Mountain Research Station. 59 p. 
Rucinski, D.K., D. Belesky, J.V. DePinto, D.J. Schwab, and D. Scavia. 2010. "A simple 1-dimensional, climate based dissolved oxygen model for the central basin of Lake Erie." Journal of Great Lakes Research 36:465-476.

Sarrias, M. and R. Daziano. 2017. "Multinomial logit models with continuous and discrete individual heterogeneity in R: the gmnl package." Journal of Statistical Software 79(2): 1-46.

Scavia, D., M. Kalcic, R.L. Muenich, J. Read, N. Aloysius, I. Bertani, C. Boles, R. Confesor, J. DePinto, M. Gildow, J. Martin, T. Redder, D. Robertson, S. Sowa, Y. Wang, and H. Yen. 2017. "Multiple models guide strategies for agricultural nutrient reductions.” Frontiers in Ecology and the Environment 15(3):126-132.

Stumpf, R.P., L.T. Johnson, T.T. Wynne, and D.B. Baker. 2016. “Forecasting annual cyanobacterial bloom biomass to inform management decisions in Lake Erie.” Journal of Great Lakes Research 42(6):1174-1183.

Sohngen, B., W. Zhang, J. Bruskotter, and B. Sheldon. 2015. Results from a 2014 Survey of Lake Erie Anglers. Report for Ohio Environmental Council. Columbus, OH: The Ohio State University

Train, K.E. 2009. Discrete choice methods with simulation: Cambridge University Press. U.S. Environmental Protection Agency (US EPA). 2015. A Compilation of Cost Data Associated with the Impacts and Control of Nutrient Pollution. Office of Water report EPA 820-F-15-096.

U.S. Fishing and Wildlife Service, and U.S. Census Bureau. "2011 national survey of fishing, hunting, and wildlife-associated recreation." 
Van Houtven, G., C. Mansfield, D.J. Phaneuf, R. von Haefen, B. Milstead, M.A. Kenny, and K.H. Reckhow. 2014. "Combining expert elicitation and stated preference methods to value ecosystem services from improved lake water quality." Ecological Economics 99:40-52.

Viscusi, W.K., J. Huber, and J. Bell. 2008. "The economic value of water quality." Environmental and Resource Economics 41:169-187.

Weicksel, S., and F. Lupi. 2013. A review of the economic benefits and costs of reducing harmful algal blooms on Lake Erie. Prepared for the International Joint Commission. East Lansing, MI: Michigan State University.

Westrick, J. A., Szlag, D. C., Southwell, B. J., and Sinclair, J. 2010. "A review of cyanobacteria and cyanotoxins removal/inactivation in drinking water treatment." Analytical and Bioanalytical Chemistry 397, 1705-1714.

Whitehead, J.C., D.J. Phaneuf, C.F. Dumas, J. Herstine, J. Hill, and B. Buerger. 2010. "Convergent validity of revealed and stated recreation behavior with quality change: a comparison of multiple and single site demands." Environmental and Resource Economics 45:91-112.

Wituszynski, D., C. Hu, F. Zhang, J. Chaffin, J. Lee, S. Ludsin, and J. Martin. 2017. "Microcystin in Lake Erie fish: risk to human health and relationship to cyanobacterial blooms.” Journal of Great Lakes Research, in press

Wolf, D., W Georgic, H.A. Klaiber., 2017. Reeling in the damages: Harmful algal blooms' impact on Lake Erie's recreational fishing industry. Journal of Environmental Management. 199: .148-157. 
Zhao, Y. M., Jones, M. L., Shuter, B. J., and Roseman, E. F. 2009. “A biophysical model of Lake Erie walleye (Sander vitreus) explains interannual variations in recruitment.” Canadian Journal of Fisheries and Aquatic Sciences 66: 114-125. 


\section{Tables}

Table 1. Comparison of Angler Characteristics of our Sample and National Sample

\begin{tabular}{|c|c|c|c|c|c|}
\hline \multirow[b]{2}{*}{ Variable } & \multirow[b]{2}{*}{ Value } & \multicolumn{2}{|c|}{ Our sample } & \multicolumn{2}{|c|}{ National sample - percent } \\
\hline & & \# Responses & Percent & $\begin{array}{c}\text { Ohio } \\
\text { resident } \\
\text { anglers }\end{array}$ & $\begin{array}{c}\text { US anglers } \\
\text { who fish in } \\
\text { the Great } \\
\text { Lakes }\end{array}$ \\
\hline \multirow{6}{*}{ Age } & 18-24 years & 12 & $1.6 \%$ & $16.1 \%$ & $19.4 \%$ \\
\hline & 25-34 years & 54 & $7.0 \%$ & $17.6 \%$ & $14.1 \%$ \\
\hline & 35-44 years & 75 & $9.8 \%$ & $13.3 \%$ & $29.3 \%$ \\
\hline & 45-54 years & 165 & $21.5 \%$ & $31.1 \%$ & $21.8 \%$ \\
\hline & 55-64 years & 196 & $25.6 \%$ & $7.1 \%$ & $8.3 \%$ \\
\hline & $65-74$ years & 265 & $34.6 \%$ & $14.7 \%$ & $7.1 \%$ \\
\hline \multirow{4}{*}{ Education } & $\begin{array}{l}11 \text { years or } \\
\text { less }\end{array}$ & 26 & $3.5 \%$ & $11.5 \%$ & \\
\hline & 12 years & 168 & $22.4 \%$ & $51.8 \%$ & $33.9 \%$ \\
\hline & $\begin{array}{l}1-3 \text { years of } \\
\text { college }\end{array}$ & 278 & $37.0 \%$ & $16.6 \%$ & $32.0 \%$ \\
\hline & $\begin{array}{l}4 \text { years or } \\
\text { more of } \\
\text { college }\end{array}$ & 279 & $37.2 \%$ & $20.1 \%$ & $34.1 \%$ \\
\hline \multirow{5}{*}{$\begin{array}{c}\text { Annual } \\
\text { household } \\
\text { income }\end{array}$} & Less than $20 \mathrm{k}$ & 59 & $8.8 \%$ & $28.0 \%$ & \\
\hline & 20-30k & 46 & $6.9 \%$ & $11.8 \%$ & \\
\hline & $30-40 \mathrm{k}$ & 85 & $12.7 \%$ & $14.2 \%$ & \\
\hline & 40-50k & 30 & $4.5 \%$ & $6.0 \%$ & $14.1 \%$ \\
\hline & $50-75 \mathrm{k}$ & 163 & $24.3 \%$ & $18.1 \%$ & $25.6 \%$ \\
\hline
\end{tabular}




\begin{tabular}{|c|c|c|c|c|c|}
\hline & $75-100 \mathrm{k}$ & 116 & $17.3 \%$ & $8.0 \%$ & $29.6 \%$ \\
\hline & $100-150 \mathrm{k}$ & 171 & $25.5 \%$ & $13.9 \%$ & $30.8 \%$ \\
\hline \multirow{4}{*}{$\begin{array}{l}\text { Population } \\
\text { size of } \\
\text { residence }\end{array}$} & $\begin{array}{l}1 \text { million or } \\
\text { more }\end{array}$ & 285 & $37.2 \%$ & $30.2 \%$ & $33.1 \%$ \\
\hline & $\begin{array}{l}250 \mathrm{k}-1 \\
\text { million }\end{array}$ & 75 & $9.8 \%$ & $32.5 \%$ & $29.1 \%$ \\
\hline & $50 \mathrm{k}-250 \mathrm{k}$ & & & $25.5 \%$ & $22.6 \%$ \\
\hline & Outside metro & 407 & $53.1 \%$ & $11.8 \%$ & $15.0 \%$ \\
\hline \multirow{2}{*}{ Gender } & Male & 672 & $89.0 \%$ & $80.1 \%$ & $75.5 \%$ \\
\hline & Female & 83 & $11.0 \%$ & $19.9 \%$ & $24.5 \%$ \\
\hline
\end{tabular}


Table 2. Model Results from CL and G-MNL-II Models

\begin{tabular}{|c|c|c|c|c|c|}
\hline \multirow[b]{2}{*}{ Variable } & \multirow[b]{2}{*}{ Explanation } & \multirow[b]{2}{*}{ CL } & \multirow[b]{2}{*}{$\begin{array}{c}\text { CL with } \\
\text { interactions }\end{array}$} & G-MNL-II & G-MNL-II with \\
\hline & & & & $\begin{array}{l}\text { with } \\
\text { normal } \\
\text { mixing }\end{array}$ & $\begin{array}{c}\text { log-normal } \\
\text { mixing for } \\
\text { walleye and hab }\end{array}$ \\
\hline Mean coefficien & & & & & \\
\hline price & $\begin{array}{l}\text { travel cost from home to } \\
\text { nearest boat ramp }(\$)\end{array}$ & $\begin{array}{c}-0.0069 * * * \\
(<0.001)\end{array}$ & $\begin{array}{c}-0.0126 * * * \\
(<0.001)\end{array}$ & $\begin{array}{c}-0.0107 * * * \\
(<0.001)\end{array}$ & $\begin{array}{c}-0.0107 * * * \\
(<0.001)\end{array}$ \\
\hline Walleye & \# hours to catch one walleye & $\begin{array}{c}-0.3205 * * * \\
(<0.001)\end{array}$ & $\begin{array}{c}-0.6805 * * * \\
(<0.001)\end{array}$ & $\begin{array}{c}-1.3984 * * * \\
(<0.001)\end{array}$ & $\begin{array}{c}-0.6697 * * * \\
(<0.001)\end{array}$ \\
\hline hab_size & $\begin{array}{l}\text { miles of algal bloom to boat } \\
\text { through }\end{array}$ & $\begin{array}{c}-0.0627 * * * \\
(<0.001)\end{array}$ & $\begin{array}{c}-0.1214 * * * \\
(<0.001)\end{array}$ & $\begin{array}{c}-0.2580 * * * \\
(<0.001)\end{array}$ & $\begin{array}{c}-2.9652 * * * \\
(<0.001)\end{array}$ \\
\hline clarity_clear & dummy for very clear water & $\begin{array}{l}0.6557 * * * \\
(<0.001)\end{array}$ & $\begin{array}{l}0.9440 * * * \\
(<0.001)\end{array}$ & $\begin{array}{l}1.8816^{* * *} \\
(<0.001)\end{array}$ & $\begin{array}{l}0.8564 * * * \\
(<0.001)\end{array}$ \\
\hline clarity_medium & $\begin{array}{l}\text { dummy for somewhat murky } \\
\text { water }\end{array}$ & $\begin{array}{l}0.4433^{* * *} \\
(<0.001)\end{array}$ & $\begin{array}{c}0.5998 * * * \\
(<0.001)\end{array}$ & $\begin{array}{l}1.0421^{* * *} \\
(<0.001)\end{array}$ & $\begin{array}{l}0.5346^{* * *} \\
(<0.001)\end{array}$ \\
\hline dist_boat & $\begin{array}{l}\text { boating distance from boat } \\
\text { ramp to fishing site (miles) }\end{array}$ & $\begin{array}{c}-0.0068 * * * \\
(<0.001)\end{array}$ & $\begin{array}{c}-0.0214 * * * \\
(<0.001)\end{array}$ & $\begin{array}{c}-0.0341 * * * \\
(<0.001)\end{array}$ & $\begin{array}{c}-0.0106 * * * \\
(<0.001)\end{array}$ \\
\hline Neither & dummy for choosing "neither" & $\begin{array}{c}-1.7484 * * * \\
(<0.001)\end{array}$ & $\begin{array}{c}-3.9268 * * * \\
(<0.001)\end{array}$ & $\begin{array}{c}-4.1455^{* * *} \\
(<0.001)\end{array}$ & $\begin{array}{c}-3.8764 * * * \\
(<0.001)\end{array}$ \\
\hline
\end{tabular}

Interaction variables 


\begin{tabular}{|c|c|c|}
\hline walleye $*$ walleye & \# hours to catch one walleye $*$ & 0.0167 \\
\hline is the key species & dummy_key species to target & $(0.86)$ \\
\hline to target & is walleye & \\
\hline$h a b \_s i z e^{* h a s}$ & miles of algal bloom to boat & 0.0208 \\
\hline seen $H A B$ & $\begin{array}{l}\text { through * dummy_has seen } \\
\text { blooms before }\end{array}$ & $(0.56)$ \\
\hline neither*male & $\begin{array}{l}\text { dummy_choose “neither” * } \\
\text { dummy_male }\end{array}$ & $\begin{array}{c}0.0661^{* * *} \\
(0.7)\end{array}$ \\
\hline neither*education & $\begin{array}{l}\text { dummy_choose “neither” * } \\
\text { education level }\end{array}$ & $\begin{array}{c}-0.2082 * * * \\
(0.6)\end{array}$ \\
\hline
\end{tabular}

\section{Standard deviation}

\begin{tabular}{|c|c|c|c|}
\hline \multirow[t]{2}{*}{ Walleye } & \# hours to catch one walleye & $0.8004 * * *$ & $1.4131^{* * *}$ \\
\hline & & $(<0.001)$ & $(<0.001)$ \\
\hline \multirow{2}{*}{ hab_size } & miles of algal bloom to boat & $0.2628 * * *$ & $1.4379 * * *$ \\
\hline & through & $(<0.001)$ & $(<0.001)$ \\
\hline \multirow[t]{2}{*}{ clarity_clear } & dummy for very clear water & $1.6118 * * *$ & $0.9073 * * *$ \\
\hline & & $(<0.001)$ & $(<0.001)$ \\
\hline \multirow[t]{2}{*}{ clarity_medium } & dummy for somewhat murky & $1.1581^{* * *}$ & $0.4966 * * *$ \\
\hline & water & $(<0.001)$ & $(<0.001)$ \\
\hline \multirow[t]{2}{*}{ dist_boat } & boating distance from boat & $0.0617 * * *$ & $0.0343 * * *$ \\
\hline & ramp to fishing site (miles) & $(<0.001)$ & $(<0.001)$ \\
\hline
\end{tabular}


Tau

scale parameter

$1.3718 * * *$

$-0.0103$

$(<0.001)$

(0.9070)

Log-likelihood

$-4502.14$

$-3784.39$

$-3650.2$

$-3679.5$

Out-of-sample prediction accuracy

$50.7 \%$

$54.0 \%$

$53.5 \%$

$55.6 \%$

AIC

9018.3

7880.7

7328.3

7387.0

BIC

9071.0

7960.7

7418.4

7477.1

Number of parameters

7

11

13

13

RMSE from k-fold cross validation

4.709

4.416

3.919

4.241

Number of observations

13806

Number of respondents

767

Note: p-values for the z-statistics of the coefficients are shown in the parentheses. 
Table 3. Latent Class Models with Four Classes

\begin{tabular}{|c|c|c|c|c|c|}
\hline Variable & Explanation & Class 1 & Class 2 & Class 3 & Class 4 \\
\hline \multicolumn{6}{|l|}{ Utility function } \\
\hline \multirow[t]{2}{*}{ price } & travel cost from home to boat & $-0.0208 *$ & $-0.0160 * * *$ & $-0.0059 * * *$ & $-0.0144 * * *$ \\
\hline & $\operatorname{ramp}(\$)$ & $(0.057)$ & $(<0.001)$ & $(<0.001)$ & $(<0.001)$ \\
\hline \multirow[t]{2}{*}{ walleye } & \# hours to catch one walleye & $-0.7091 * *$ & $-1.1674 * * *$ & -0.036 & $-0.4753 * * *$ \\
\hline & & $(0.018$ & $(<0.001)$ & $(0.201)$ & $(<0.001)$ \\
\hline \multirow[t]{2}{*}{ hab_size } & miles of algal bloom to boat & $-0.2272 * *$ & $-0.1542 * * *$ & $-0.0455^{* * *}$ & $-0.1588 * * *$ \\
\hline & through & $(0.057)$ & $(<0.001)$ & $(<0.001)$ & $(<0.001)$ \\
\hline \multirow[t]{2}{*}{ clarity_clear } & dummy for very clear water & 0.5911 & $0.7567 * * *$ & $0.5089 * * *$ & $1.7339 * * *$ \\
\hline & & $(0.280)$ & $(<0.001)$ & $(<0.001)$ & $(<0.001)$ \\
\hline \multirow[t]{2}{*}{ clarity_medium } & dummy for somewhat murky & -0.2498 & $0.6027 * * *$ & $0.4299 * * *$ & $1.0100 * * *$ \\
\hline & water & $(0.688)$ & $(<0.001)$ & $(<0.001)$ & $(<0.001)$ \\
\hline \multirow[t]{2}{*}{ dist_boat } & boating distance from boat & 0.0161 & $-0.0297 * * *$ & -0.0007 & $-0.0145 * * *$ \\
\hline & ramp to fishing site (miles) & $(0.486)$ & $(<0.001)$ & $(0.819)$ & $(<0.001)$ \\
\hline \multirow[t]{2}{*}{ neither } & dummy for choosing & -0.8202 & $-7.7773 * * *$ & $-3.0586 * * *$ & $-1.6675 * * *$ \\
\hline & "neither" & $(0.517)$ & $(<0.001)$ & $(<0.001)$ & $(<0.001)$ \\
\hline \multicolumn{6}{|c|}{ Class membership function } \\
\hline \multirow[t]{2}{*}{ age } & age of respondent & $-0.0292 * *$ & $-0.0294 * *$ & -0.0117 & \\
\hline & & $(0.026)$ & $(0.025)$ & $(0.394)$ & \\
\hline
\end{tabular}




\begin{tabular}{|c|c|c|c|c|c|}
\hline \multirow[t]{2}{*}{ education } & highest level of & -0.2134 & $0.2161^{*}$ & -0.1674 & \\
\hline & education & $(0.152)$ & $(0.086)$ & $(0.185)$ & \\
\hline \multirow[t]{2}{*}{ employed } & working or self- & $-1.4289 * *$ & -0.9181 & -0.9207 & \\
\hline & employed & $(0.024)$ & $(0.131)$ & $(0.135)$ & \\
\hline \multirow[t]{2}{*}{ male } & dummy for male & -0.1516 & -0.2448 & -0.0792 & \\
\hline & & $(0.338)$ & $(0.530)$ & $(0.843)$ & \\
\hline \multirow[t]{2}{*}{ household income } & household income & $-1.02 \mathrm{E}-06$ & 5.41E-06 & $-7.82 \mathrm{E}-07$ & \\
\hline & & $(0.811)$ & $(0.103)$ & $(0.815)$ & \\
\hline \multirow[t]{2}{*}{ married } & dummy for & 0.2047 & 0.3439 & $0.5054^{*}$ & \\
\hline & married & $(0.553)$ & $(0.245)$ & $(0.084)$ & \\
\hline \multirow[t]{2}{*}{ retired } & dummy for retired & -0.6340 & -0.8665 & -0.4748 & \\
\hline & & $(0.338)$ & $(0.192)$ & $(0.459)$ & \\
\hline \multirow[t]{2}{*}{ constant } & intercept & $2.8177 * * *$ & 1.6090 & $1.7539 *$ & \\
\hline & & $(0.005)$ & $(0.107)$ & $(0.091)$ & \\
\hline \multicolumn{2}{|l|}{ Latent class share } & 0.136 & 0.306 & 0.322 & 0.235 \\
\hline \multicolumn{3}{|l|}{ Log-likelihood } & \multicolumn{3}{|c|}{-3328.36} \\
\hline \multicolumn{3}{|c|}{ Out-of-sample prediction accuracy (\%) } & \multicolumn{3}{|c|}{$54.8 \%$} \\
\hline \multicolumn{3}{|l|}{ AIC } & \multicolumn{3}{|c|}{6946.7} \\
\hline \multicolumn{3}{|l|}{$\mathrm{BIC}$} & \multicolumn{3}{|c|}{7023.1} \\
\hline \multicolumn{3}{|l|}{ Degree of freedom } & \multicolumn{3}{|c|}{52} \\
\hline \multicolumn{3}{|c|}{ RSME from a k-fold cross validation } & \multicolumn{3}{|c|}{4.012} \\
\hline
\end{tabular}


Number of observations

Number of respondents
13806

767

Note: p-values for the z-statistics of the coefficients are shown in the parentheses. 
Table 4. Heterogeneity in WTP across Various Models

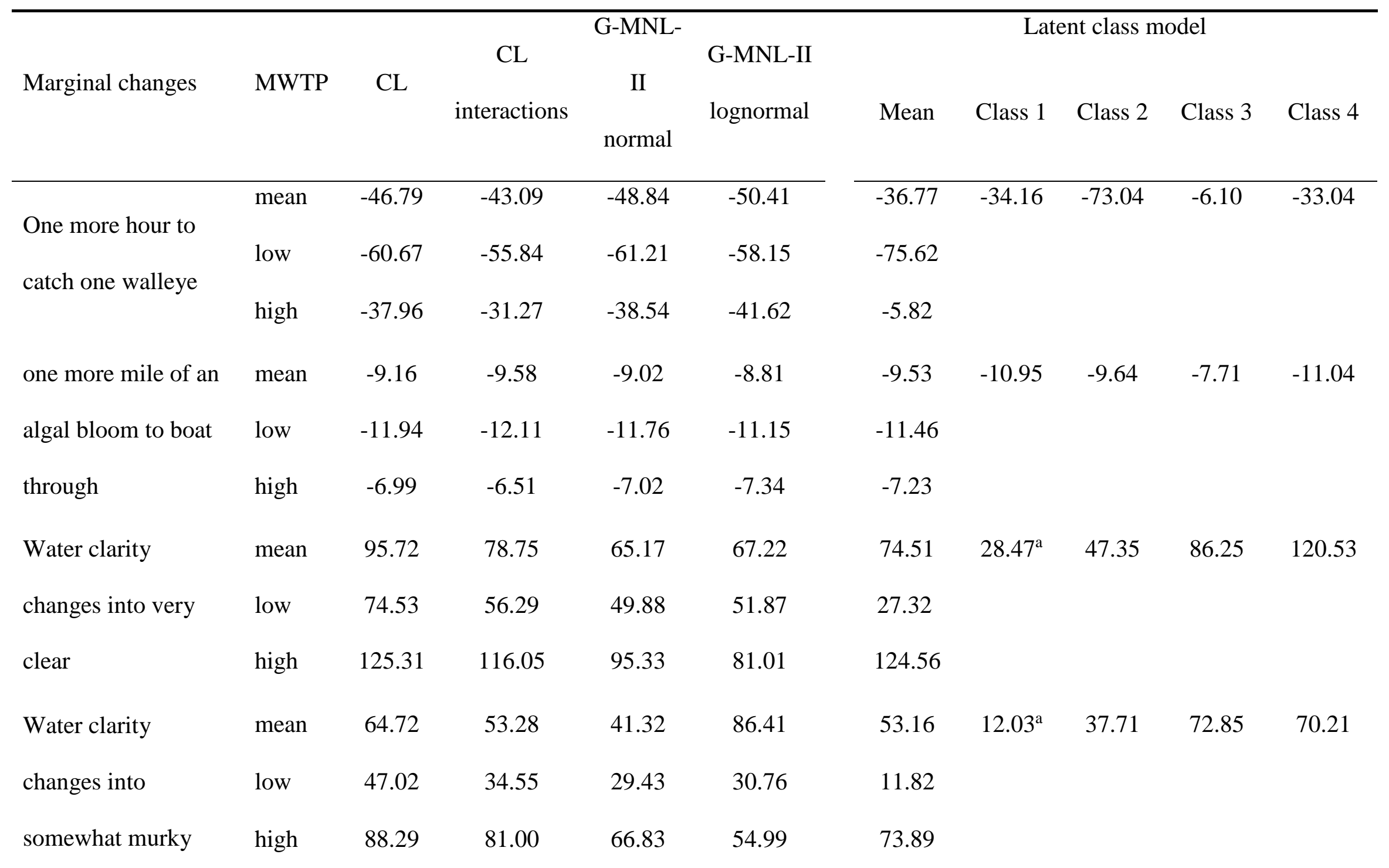




\begin{tabular}{|c|c|c|c|c|c|c|c|c|c|c|}
\hline One more mile from & mean & -0.99 & -0.69 & -1.30 & -1.30 & -0.74 & $0.77^{\mathrm{a}}$ & -1.86 & $-0.12^{\mathrm{a}}$ & -1.01 \\
\hline
\end{tabular}

Note: MWTP is marginal willingness to pay. Low and high are the lower and higher bound of the $99^{\text {th }}$ confidence interval.

${ }^{\text {a }}$ denotes the WTP that is not statistically significant. 
Table 5. Impacts of Different Nutrient Management Policies on Water Quality Variables

\begin{tabular}{cccccc}
\hline \multirow{2}{*}{ Number } & Policy scenario & \multicolumn{5}{c}{ Variable values } \\
& Description & walleye & hab_size & clarity_clear & clarity_medium \\
\hline & baseline & 2.2 & 3 & 0 & 1 \\
1 & $10 \%$ reduction in Maumee DRP loading & 2.2 & 3 & 0.2 & 0.8 \\
2 & $20 \%$ reduction in Maumee DRP loading & 2.2 & 2.5 & 0.3 & 0.7 \\
3 & $40 \%$ reduction in Maumee DRP loading & 2.2 & 1 & 0.7 & 0.3 \\
\hline
\end{tabular}

Note: DRP denotes dissolved reactive phosphorus in the spring. 
Table 6. Distribution of Welfare Effects across Nutrient Management Scenarios and Models

\begin{tabular}{|c|c|c|c|c|c|c|}
\hline $\begin{array}{l}\text { Policy } \\
\text { \% reduction }\end{array}$ & CV & CL & $\begin{array}{c}\text { CL with } \\
\text { interactions }\end{array}$ & $\begin{array}{c}\text { G-MNL-II } \\
\text { normal }\end{array}$ & $\begin{array}{l}\text { G-MNL-II } \\
\text { lognormal }\end{array}$ & LCM \\
\hline & mean & 7.81 & 6.41 & 6.34 & 6.55 & 6.78 \\
\hline & std dev & & & 18.67 & 11.63 & 9.42 \\
\hline \multirow{5}{*}{10} & median & & & 4.72 & 4.81 & 3.26 \\
\hline & low & & & -55.49 & 0.13 & 2.03 \\
\hline & high & & & 69.47 & 23.26 & 38.59 \\
\hline & mean & 17.63 & 16.34 & 15.34 & 16.06 & 15.21 \\
\hline & std dev & & & 31.18 & 24.27 & 15.20 \\
\hline \multirow{5}{*}{20} & median & & & 12.71 & 13.10 & 9.49 \\
\hline & low & & & -47.07 & 2.56 & 3.58 \\
\hline & high & & & 122.07 & 35.28 & 65.40 \\
\hline & mean & 50.03 & 49.33 & 40.41 & 53.56 & 60.46 \\
\hline & std dev & & & 65.00 & 66.97 & 50.85 \\
\hline \multirow[t]{3}{*}{40} & median & & & 25.12 & 48.39 & 59.30 \\
\hline & low & & & -114.79 & 10.23 & 14.46 \\
\hline & high & & & 304.19 & 129.13 & 237.36 \\
\hline
\end{tabular}

Note: std dev denotes standard deviation of the compensating variation distribution across

individual anglers, while low and high are the lower and higher bound of $99^{\text {th }}$ confidence interval of compensating variation. 
Figures

Figure 1. Study area - western Lake Erie basin.

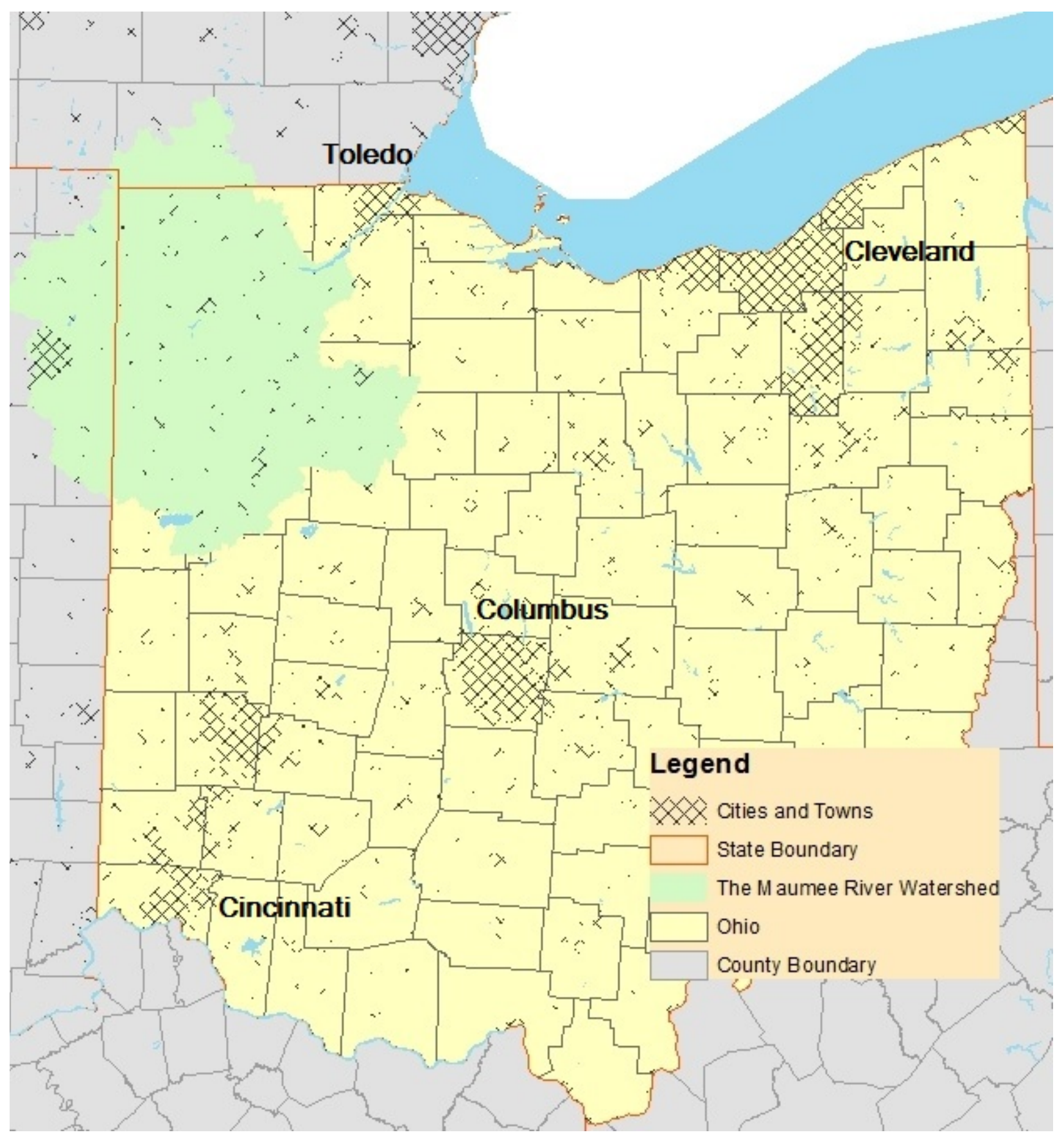


Figure 2. One example of choice scenario in the choice experiment.

Scenario 1 (9):

In the following scenario, two potential sites for walleye fishing are presented. Please review the attribute levels for each site, and decide which site you would prefer. Check the box below the particular site for the one you would choose. You can choose neither by checking the box "Neither".

\begin{tabular}{l|c|c|c}
\hline Attribute & Site A & Site B & Neither \\
\hline $\begin{array}{l}\text { Walleye catch rate at fishing site } \\
\text { (\# hours needed per fish caught per person) }\end{array}$ & 6 hours & 2 hours & \\
\hline $\begin{array}{l}\text { Miles of an algal bloom that you have to boat } \\
\text { through before getting to the fishing site (0, 4, 8) }\end{array}$ & 8 & 0 & \\
\hline $\begin{array}{l}\text { Poor water clarity caused by sediments at fishing } \\
\text { site (Very murky, somewhat murky, clear) }\end{array}$ & Very Clear & Very Murky & \\
\hline $\begin{array}{l}\text { Time in boat getting to fishing site (minutes) } \\
\text { Distance from house to boat ramp (miles) }\end{array}$ & 30 & 45 & \\
\hline $\begin{array}{l}\text { Which Site do you MOST prefer (Please } \\
\text { check the box for your preferred option) }\end{array}$ & Site A & Site B & \multirow{2}{*}{\begin{tabular}{c} 
NEITHER \\
\cline { 2 - 4 }
\end{tabular}} \\
\hline
\end{tabular}




\section{AJAE appendix for Do US anglers care about harmful algal blooms? A discrete choice experiment of Lake Erie recreational anglers"}

Authors:

Wendong Zhang, Assistant Professor of Economics, Iowa State University, wdzhang@iastate.edu; and

Brent Sohngen, Professor of Agricultural, Environmental and Development Economics, the Ohio State University, Sohngen.1@osu.edu

Date: 01/19/2018

Note: The material contained herein is supplementary to the article named in the title and published in the American Journal of Agricultural Economics (AJAE). 
Table A1. Model results with S-MNL and RPL

\begin{tabular}{|c|c|c|c|c|c|}
\hline Variable & Explanation & $\begin{array}{c}\text { S-MNL } \\
\text { price scaled }\end{array}$ & $\begin{array}{l}\text { S-MNL } \\
\text { price } \\
\text { unscaled }\end{array}$ & $\begin{array}{l}\text { RPL - } \\
\text { normal }\end{array}$ & $\begin{array}{c}\text { RPL - } \\
\text { lognormal } \\
\text { for walleye } \\
\text { and hab }\end{array}$ \\
\hline Mean coefficient & & & & & \\
\hline price & $\begin{array}{l}\text { travel cost from home to } \\
\text { nearest boat ramp }(\$)\end{array}$ & $\begin{array}{l}-0.0163 * * * \\
(<0.001)\end{array}$ & $\begin{array}{l}-0.0084^{* * *} \\
(<0.001)\end{array}$ & $\begin{array}{l}-0.0126 * * * \\
(<0.001)\end{array}$ & $\begin{array}{l}-5.2931 * * * \\
(<0.001)\end{array}$ \\
\hline walleye & $\begin{array}{l}\text { \# hours to catch one } \\
\text { walleye }\end{array}$ & $\begin{array}{l}-0.7353 * * * \\
(<0.001)\end{array}$ & $\begin{array}{l}-0.8929 * * * \\
(<0.001)\end{array}$ & $\begin{array}{l}-0.6805 * * * \\
(<0.001)\end{array}$ & $\begin{array}{l}-0.7967 * * * \\
(<0.001)\end{array}$ \\
\hline hab_size & $\begin{array}{l}\text { miles of algal bloom to } \\
\text { boat through }\end{array}$ & $\begin{array}{l}-0.1548 * * * \\
(<0.001)\end{array}$ & $\begin{array}{l}-0.1852 * * * \\
(<0.001)\end{array}$ & $\begin{array}{l}-0.1214 * * * \\
(<0.001)\end{array}$ & $\begin{array}{l}-3.2359 * * * \\
(<0.001)\end{array}$ \\
\hline clarity_clear & $\begin{array}{l}\text { dummy for very clear } \\
\text { water }\end{array}$ & $\begin{array}{l}1.1045^{* * *} \\
(<0.001)\end{array}$ & $\begin{array}{l}1.0513 * * * \\
(<0.001)\end{array}$ & $\begin{array}{l}0.9440 * * * \\
(<0.001)\end{array}$ & $\begin{array}{l}0.8504^{* * *} \\
(<0.001)\end{array}$ \\
\hline clarity_medium & $\begin{array}{l}\text { dummy for somewhat } \\
\text { murky water }\end{array}$ & $\begin{array}{l}0.6105^{* * *} \\
(<0.001)\end{array}$ & $\begin{array}{l}0.4939 * * * \\
(<0.001)\end{array}$ & $\begin{array}{l}0.5998 * * * \\
(<0.001)\end{array}$ & $\begin{array}{l}0.5524 * * * \\
(<0.001)\end{array}$ \\
\hline dist_boat & $\begin{array}{l}\text { boating distance from } \\
\text { boat ramp to fishing site } \\
\text { (miles) }\end{array}$ & $\begin{array}{l}-0.0230 * * * \\
(<0.001)\end{array}$ & $\begin{array}{l}-0.0286 * * * \\
(<0.001)\end{array}$ & $-0.0214 * * *$ & $\begin{array}{l}-0.0116^{* * *} \\
(<0.001)\end{array}$ \\
\hline neither & $\begin{array}{l}\text { dummy for choosing } \\
\text { "neither" }\end{array}$ & $\begin{array}{l}-3.8531 * * * \\
(<0.001)\end{array}$ & $\begin{array}{l}-3.8061 * * * \\
(<0.001)\end{array}$ & $\begin{array}{l}-3.9268 * * * \\
(<0.001)\end{array}$ & $\begin{array}{l}-3.9802 * * * \\
(<0.001)\end{array}$ \\
\hline
\end{tabular}




\begin{tabular}{|c|c|c|c|c|c|}
\hline \multicolumn{6}{|c|}{ Standard deviation } \\
\hline \multirow[t]{2}{*}{ price } & \multicolumn{4}{|l|}{ travel cost from home to } & $-2.5044 * * *$ \\
\hline & \multicolumn{4}{|l|}{ nearest boat ramp (\$) } & $(<0.001)$ \\
\hline \multirow[t]{2}{*}{ walleye } & \multicolumn{3}{|l|}{ \# hours to catch one } & $0.5633^{* * *}$ & $0.9362 * * *$ \\
\hline & \multicolumn{3}{|l|}{ walleye } & $(<0.001)$ & $(<0.001)$ \\
\hline \multirow[t]{2}{*}{ hab_size } & \multicolumn{3}{|l|}{ miles of algal bloom to } & $0.1734^{* * *}$ & $0.0247 * * *$ \\
\hline & \multicolumn{3}{|l|}{ boat through } & $(<0.001)$ & $(<0.001)$ \\
\hline \multirow[t]{2}{*}{ clarity_clear } & \multicolumn{3}{|l|}{ dummy for very clear } & $1.1728 * * *$ & $-0.7321 * * *$ \\
\hline & \multicolumn{3}{|l|}{ water } & $(<0.001)$ & $(<0.001)$ \\
\hline \multirow[t]{2}{*}{ clarity_medium } & \multicolumn{3}{|l|}{ dummy for somewhat } & $-0.5414 * * *$ & $0.4520 * * *$ \\
\hline & \multicolumn{3}{|l|}{ murky water } & $(<0.001)$ & $(<0.001)$ \\
\hline \multirow[t]{3}{*}{ dist_boat } & \multicolumn{3}{|l|}{ boating distance from } & $-0.0615^{* * *}$ & $0.0247^{*}$ \\
\hline & \multicolumn{5}{|l|}{ boat ramp to fishing site } \\
\hline & \multicolumn{3}{|l|}{ (miles) } & $(<0.001)$ & $(0.076)$ \\
\hline \multirow[t]{2}{*}{ tau } & \multirow[t]{2}{*}{ scale parameter } & $1.1225^{* * *}$ & $1.3401 * * *$ & & \\
\hline & & $(<0.001)$ & $(<0.001)$ & & \\
\hline \multicolumn{2}{|l|}{ Log-likelihood } & -3429.36 & -3746.26 & -3784.39 & -3659.85 \\
\hline \multicolumn{2}{|c|}{ Out-of-sample prediction accuracy (\%) } & $53.5 \%$ & $52.7 \%$ & $54.0 \%$ & $53.1 \%$ \\
\hline \multicolumn{2}{|l|}{ AIC } & 7892.6 & 7727.4 & 7433.6 & 7445.7 \\
\hline \multicolumn{2}{|l|}{ BIC } & 7926.1 & 7785.3 & 7479.2 & 7493.3 \\
\hline \multicolumn{2}{|c|}{ Number of parameters } & 8 & 8 & 12 & 13 \\
\hline
\end{tabular}




\begin{tabular}{|c|c|c|c|c|}
\hline RME & 4.562 & 4.498 & 4.357 & 4.402 \\
\hline Number of observations & & & 13806 & \\
\hline Number of respondents & & & 767 & \\
\hline
\end{tabular}

Note: p-values for the z-statistics of the coefficients are shown in the parentheses. 
Table A1.1. Model results with RPL with correlated random parameters

\begin{tabular}{|c|c|c|c|c|c|}
\hline \multirow[b]{2}{*}{ Variable } & \multirow[b]{2}{*}{ Explanation } & \multicolumn{2}{|c|}{ RPL normal - correlated } & \multicolumn{2}{|c|}{ RPL lognormal - correlated } \\
\hline & & Mean coef & $\begin{array}{l}\text { standard } \\
\text { error }\end{array}$ & Mean coef & $\begin{array}{l}\text { standard } \\
\text { error }\end{array}$ \\
\hline price & $\begin{array}{l}\text { travel cost from home to } \\
\text { nearest boat ramp (\$) }\end{array}$ & $-0.0113 * * *$ & 0.0011 & $-0.0100 * * *$ & 0.0010 \\
\hline walleye & \# hours to catch one walleye & $-0.6440 * * *$ & 0.0353 & $-0.6386 * * *$ & 0.0661 \\
\hline hab_size & $\begin{array}{l}\text { miles of algal bloom to boat } \\
\text { through }\end{array}$ & $-0.1361 * * *$ & 0.0120 & $-2.8136 * * *$ & 0.2069 \\
\hline clarity_clear & dummy for very clear water & $0.9521^{* * *}$ & 0.0958 & $1.0359 * * *$ & 0.0879 \\
\hline clarity_medium & $\begin{array}{l}\text { dummy for somewhat murky } \\
\text { water }\end{array}$ & $0.4914^{* * *}$ & 0.0790 & $0.5636^{* * *}$ & 0.0742 \\
\hline dist_boat & $\begin{array}{l}\text { boating distance from boat } \\
\text { ramp to fishing site (miles) }\end{array}$ & $-0.0219 * * *$ & 0.0031 & $-0.0140^{* * *}$ & 0.0027 \\
\hline neither & dummy for choosing "neither" & $-4.0063 * * *$ & 0.1609 & $-3.8722^{* * *}$ & 0.1532 \\
\hline 111 & & $-1.0684^{* * *}$ & 0.1316 & $1.0679 * * *$ & 0.1248 \\
\hline 121 & & $-0.3194 *$ & 0.1647 & 0.2281 & 0.1400 \\
\hline 131 & & 0.0019 & 0.0069 & $-0.0110^{* *}$ & 0.0042 \\
\hline 141 & & 0.0336 & 0.0274 & $1.0168 * * *$ & 0.1658 \\
\hline 151 & & 0.1286 & 0.0846 & $0.4203^{* * *}$ & 0.0665 \\
\hline 122 & & $0.3924^{* * *}$ & 0.1074 & 0.1462 & 0.1311 \\
\hline 132 & & $0.0431^{* * *}$ & 0.0040 & $0.0257 * * *$ & 0.0036 \\
\hline 142 & & $0.1432^{* * *}$ & 0.0203 & $-0.9937 * * *$ & 0.1502 \\
\hline 152 & & $0.2758^{* * *}$ & 0.0923 & -0.0375 & 0.0829 \\
\hline 133 & & -0.0124 & 0.0086 & 0.0100 & 0.0084 \\
\hline 143 & & -0.0389 & 0.0594 & $0.6079 * * *$ & 0.1486 \\
\hline 153 & & 0.1603 & 0.1510 & $0.1671^{*}$ & 0.0949 \\
\hline 144 & & -0.0322 & 0.0431 & $0.6329 * * *$ & 0.1614 \\
\hline 154 & & 0.0329 & 0.0823 & $1.1967^{* * *}$ & 0.0984 \\
\hline 155 & & $0.4162 * * *$ & 0.1073 & $0.5204^{* * *}$ & 0.0662 \\
\hline \multicolumn{2}{|l|}{ Log-likelihood } & \multicolumn{2}{|c|}{-3720.5} & \multicolumn{2}{|c|}{-3655.5} \\
\hline \multicolumn{2}{|c|}{ Out-of-sample prediction accuracy (\%) } & \multicolumn{2}{|c|}{$53.60 \%$} & \multicolumn{2}{|c|}{$54.20 \%$} \\
\hline \multicolumn{2}{|l|}{ AIC } & \multicolumn{2}{|c|}{7484.9} & \multicolumn{2}{|c|}{7355.0} \\
\hline \multicolumn{2}{|l|}{ BIC } & \multicolumn{2}{|c|}{7650.7} & \multicolumn{2}{|c|}{7520.8} \\
\hline \multicolumn{2}{|c|}{ Number of parameters } & \multicolumn{2}{|c|}{22} & \multicolumn{2}{|c|}{22} \\
\hline
\end{tabular}


RME

Number of observations

Number of respondents
4.361

4.122

Note: the 111-155 are elements of the lower-triangular matrix L. 
Table A2. Marginal WTP for alternative discrete choice models shown in table A1

\begin{tabular}{|c|c|c|c|c|c|c|c|}
\hline Marginal changes & MWTP & $\begin{array}{l}\text { S-MNL } \\
\text { price } \\
\text { scaled }\end{array}$ & $\begin{array}{l}\text { S-MNL price } \\
\text { unscaled }\end{array}$ & $\begin{array}{l}\text { RPL - } \\
\text { normal }\end{array}$ & $\begin{array}{c}\text { RPL - } \\
\text { lognormal } \\
\text { for walleye } \\
\text { and hab }\end{array}$ & $\begin{array}{c}\text { RPL - } \\
\text { normal, } \\
\text { correlated }\end{array}$ & $\begin{array}{c}\text { RPL - } \\
\text { lognormal, } \\
\text { correlated }\end{array}$ \\
\hline \multirow{3}{*}{$\begin{array}{l}\text { One more hour to } \\
\text { catch one walleye }\end{array}$} & mean & -45.05 & -51.88 & -53.96 & -60.33 & -57.03 & -53.18 \\
\hline & low & -53.36 & -62.48 & -64.56 & -69.23 & -74.80 & -65.93 \\
\hline & high & -36.73 & -30.55 & -43.36 & -45.22 & -44.08 & -42.35 \\
\hline one more mile of & mean & -9.48 & -11.20 & -9.63 & -14.32 & -12.05 & -7.96 \\
\hline an algal bloom to & low & -11.52 & -13.11 & -11.96 & -16.15 & -16.24 & -10.68 \\
\hline boat through & high & -7.44 & -6.33 & -7.30 & -8.34 & -8.94 & -5.49 \\
\hline Water clarity & mean & 67.67 & 58.57 & 74.85 & 77.77 & 84.31 & 104.11 \\
\hline changes into very & low & 53.55 & 46.92 & 56.53 & 49.64 & 58.68 & 78.61 \\
\hline clear & high & 81.78 & 96.22 & 93.17 & 86.58 & 113.89 & 129.60 \\
\hline Water clarity & mean & 37.40 & 41.65 & 47.56 & 49.38 & 43.51 & 56.64 \\
\hline changes into & low & 25.97 & 29.33 & 33.28 & 30.04 & 24.94 & 38.79 \\
\hline somewhat murky & high & 48.83 & 52.04 & 61.84 & 57.22 & 64.08 & 74.49 \\
\hline One more mile & mean & -1.41 & -0.92 & -1.70 & -1.04 & -1.94 & -1.40 \\
\hline from boat ramp to & low & -1.82 & -1.25 & -2.31 & -1.84 & -2.87 & -2.00 \\
\hline fishing site & high & -1.00 & -0.67 & -1.09 & -0.52 & -1.22 & -0.79 \\
\hline
\end{tabular}

Note: MWTP is marginal willingness to pay. Low and high are the lower and higher bound of the $99^{\text {th }}$ confidence interval; ${ }^{\text {a }}$ denotes the WTP that is not statistically significant. 
Table A3. CV distribution for alternative discrete choice models shown in table A1

\begin{tabular}{|c|c|c|c|c|c|c|c|}
\hline $\begin{array}{l}\text { Policy } \\
\text { \% reduction }\end{array}$ & CV & $\begin{array}{l}\text { S-MNL } \\
\text { price } \\
\text { scaled }\end{array}$ & $\begin{array}{l}\text { S-MNL } \\
\text { price } \\
\text { unscaled }\end{array}$ & $\begin{array}{l}\text { RPL - } \\
\text { normal }\end{array}$ & $\begin{array}{c}\text { RPL - } \\
\text { lognormal for } \\
\text { walleye and hab }\end{array}$ & $\begin{array}{c}\text { RPL - } \\
\text { normal - } \\
\text { correlated }\end{array}$ & $\begin{array}{c}\text { RPL - } \\
\text { lognormal - } \\
\text { correlated }\end{array}$ \\
\hline & mean & 5.63 & 8.28 & 4.61 & 4.91 & 5.37 & 7.55 \\
\hline & std dev & 11.50 & 6.96 & 9.20 & 3.14 & 10.55 & 4.62 \\
\hline \multirow[t]{5}{*}{10} & median & 5.20 & 5.66 & 4.11 & 2.80 & 4.72 & 5.24 \\
\hline & low & -24.58 & 1.64 & -16.46 & 1.94 & -15.89 & 2.33 \\
\hline & high & 30.83 & 34.52 & 27.04 & 10.06 & 28.55 & 13.84 \\
\hline & mean & 13.31 & 17.45 & 11.14 & 12.15 & 12.67 & 15.53 \\
\hline & std dev & 17.64 & 12.59 & 13.89 & 5.22 & 15.12 & 7.49 \\
\hline \multirow[t]{5}{*}{20} & median & 13.13 & 12.88 & 10.47 & 8.35 & 12.07 & 11.36 \\
\hline & low & -34.03 & 3.83 & -20.89 & 7.72 & -18.88 & 8.72 \\
\hline & high & 54.99 & 56.42 & 46.51 & 20.60 & 47.72 & 24.87 \\
\hline & mean & 51.25 & 58.90 & 48.77 & 38.76 & 49.55 & 57.47 \\
\hline & std dev & 40.81 & 70.92 & 79.90 & 14.60 & 82.37 & 28.33 \\
\hline \multirow[t]{3}{*}{40} & median & 29.91 & 34.55 & 31.49 & 28.07 & 34.21 & 39.89 \\
\hline & low & 18.57 & 6.89 & -161.68 & 26.13 & -125.49 & 32.75 \\
\hline & high & 127.75 & 394.71 & 331.05 & 62.30 & 340.16 & 95.42 \\
\hline
\end{tabular}


Table A4. CV for G-MNL-normal based on alternative angler samples and alternative gasoline cost and wage rate parameters

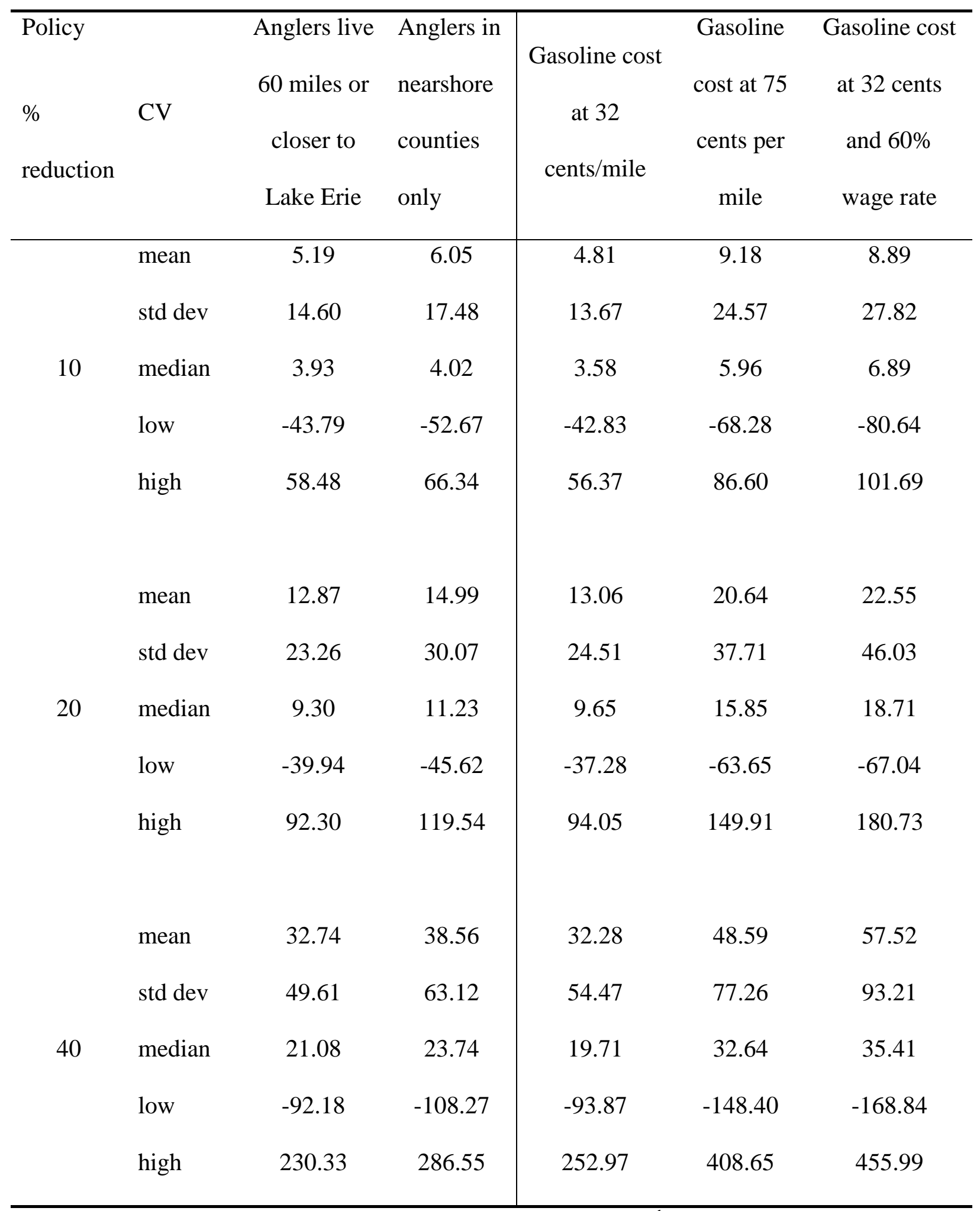

Note: low and high denotes the lower and higher bound of the $99^{\text {th }}$ confidence interval. 
Table A5. CV for G-MNL-normal model based on alternative aggregation weights and different average $\mathrm{CV}$ measures for anglers in nearshore counties

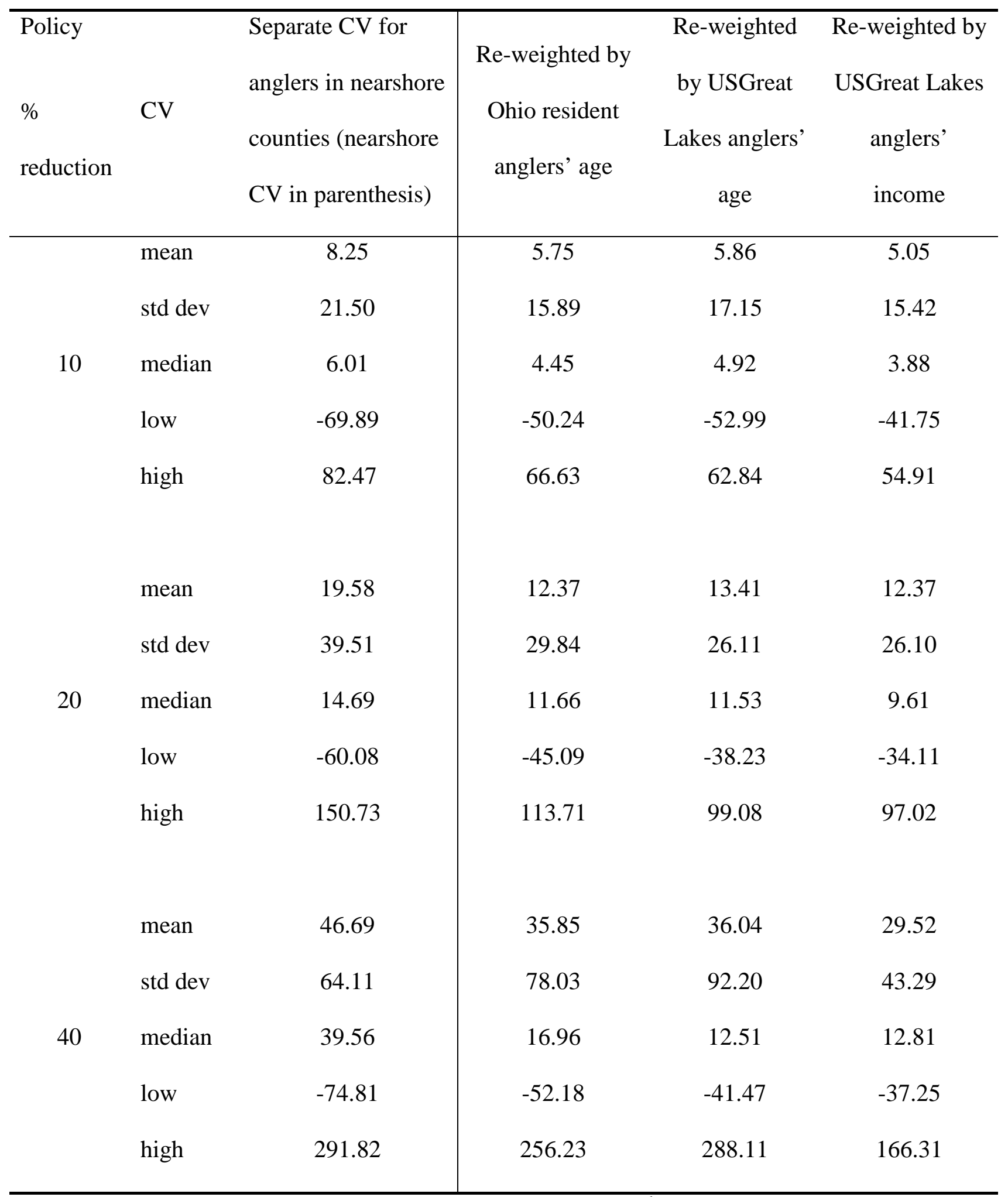

Note: low and high denotes the lower and higher bound of the $99^{\text {th }}$ confidence interval. 
Table A6. CV for G-MNL-normal model based on alternative water quality impacts from the $40 \%$ phosphorus loading reduction policy

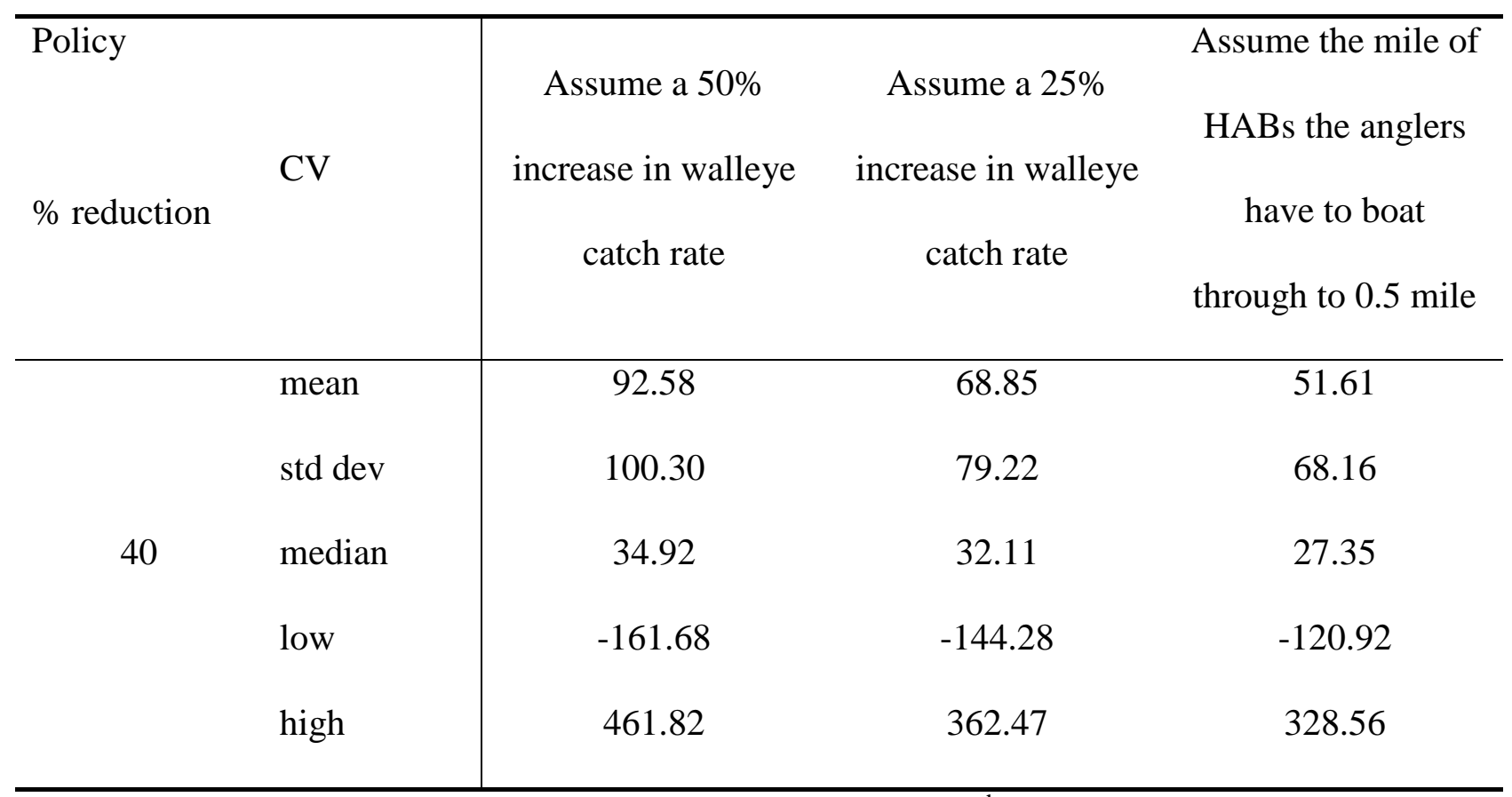

Note: low and high denotes the lower and higher bound of the $99^{\text {th }}$ confidence interval. 
Table A7. Estimation results from the travel cost model

\section{Western Basin}

\begin{tabular}{lcccc} 
& Spring & Summer & \multicolumn{1}{c}{ Fall } & Combined \\
\hline Intercept & -0.030 & $1.595^{* * *}$ & $0.625^{* * *}$ & $1.935^{* * *}$ \\
$\begin{array}{l}\text { Travel cost to own site } \\
\text { Travel cost to substitute }\end{array}$ & -0.001 & $-0.073^{* * *}$ & $-0.017^{* * * *}$ & $-0.026^{* * *}$ \\
$\begin{array}{l}\text { site } \\
\begin{array}{l}\text { Household income } \\
\text { (\$10000) }\end{array}\end{array}$ & $-0.003^{* *}$ & $0.043^{* * *}$ & $0.012^{* * *}$ & $0.015^{* * *}$ \\
\hline $\begin{array}{l}\text { Psuedo R } \\
2\end{array}$ & 0.001 & $0.026^{* * *}$ & $0.026^{* * *}$ & $0.021^{* * *}$ \\
\hline Number of observations & 0.009 & 0.133 & 0.178 & 0.149 \\
& 744 & 744 & 744 & 744 \\
\hline
\end{tabular}

\section{Central Basin}

\begin{tabular}{lcccc} 
& Spring & Summer & Fall & Combined \\
\hline Intercept & $0.796^{* * *}$ & $1.857^{* * *}$ & $0.636^{* * *}$ & $2.503^{* * *}$ \\
$\begin{array}{l}\text { Travel cost to own site } \\
\begin{array}{l}\text { Travel cost to substitute } \\
\text { site }\end{array}\end{array}$ & $-0.033^{* * *}$ & $-0.04^{* * *}$ & $-0.027^{* * *}$ & $-0.033^{* * *}$ \\
$\begin{array}{l}\text { Household income } \\
(\$ 10000)\end{array}$ & $0.017^{* * *}$ & $0.035^{* * *}$ & $0.013^{* * *}$ & $0.017^{* * *}$ \\
\hline $\begin{array}{l}\text { Psuedo } \mathrm{R}^{2} \\
\text { Number of observations }\end{array}$ & $0.007^{* * *}$ & $0.015^{* *}$ & $0.032^{* * *}$ & $0.027^{* * *}$ \\
\hline
\end{tabular}


Table A8. Consumer surplus by trip based on the travel cost model presented in Table A7, predicted trips and seasonal consumer surplus

\begin{tabular}{ccccc}
\hline Region & Season & $\begin{array}{c}\text { Average } \\
\text { Consumer } \\
\text { Surplus per } \\
\text { trip }\end{array}$ & $\begin{array}{c}\text { average } \\
\text { predicted trips }\end{array}$ & $\begin{array}{c}\text { Avg Seasonal } \\
\text { Consumer } \\
\text { Surplus }\end{array}$ \\
\hline Western Basin & spring & & 0.71 & \\
Western Basin & summer & $\$ 13.73$ & 4.17 & $\$ 57.23$ \\
Western Basin & fall & $\$ 58.81$ & 1.79 & $\$ 105.28$ \\
Western Basin & all year & $\$ 38.78$ & 6.66 & $\$ 258.25$ \\
\hline Central Basin & spring & $\$ 30.54$ & 0.78 & $\$ 23.82$ \\
Central Basin & summer & $\$ 25.21$ & 3.44 & $\$ 86.74$ \\
Central Basin & fall & $\$ 37.67$ & 1.86 & $\$ 70.06$ \\
Central Basin & all year & $\$ 30.01$ & 6.08 & $\$ 182.43$ \\
\hline
\end{tabular}


Figure A1. Distribution of marginal WTP for one less mile of HAB.

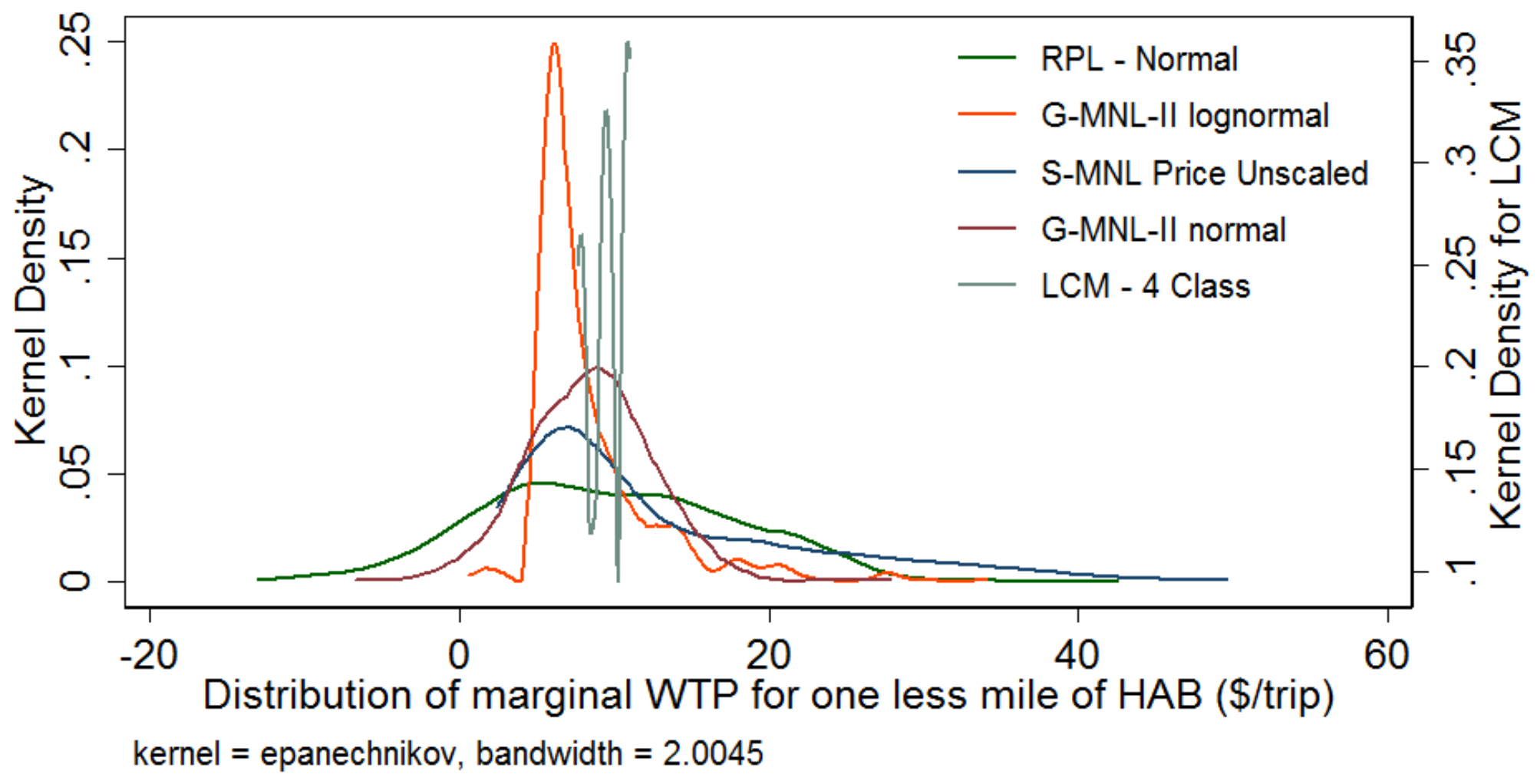


Figure A2. Distribution of re-weighted CV for a 40\% nutrient reduction policy (\$/trip)

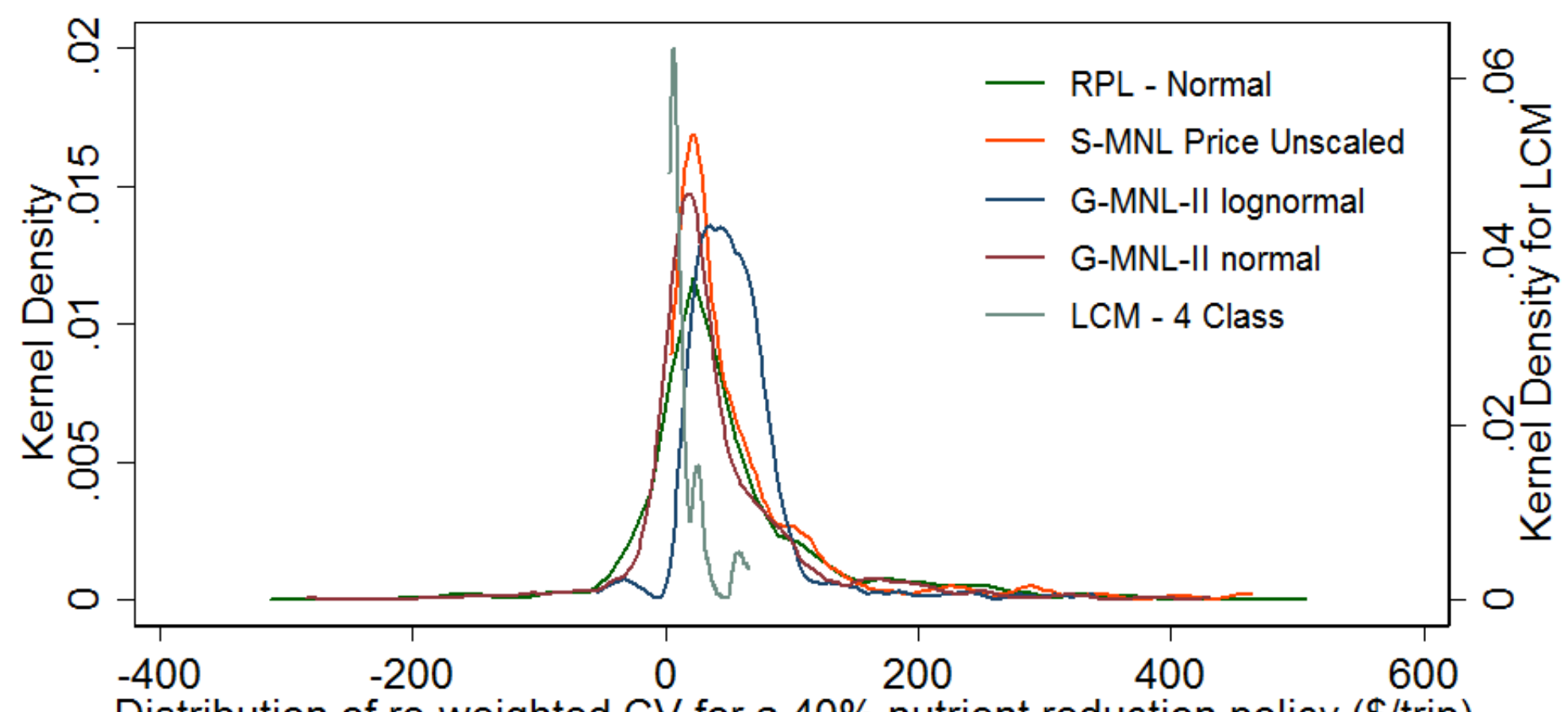

Distribution of re-weighted CV for a $40 \%$ nutrient reduction policy (\$/trip) kernel $=$ epanechnikov, bandwidth $=9.5920$ 


\section{Grouped Endnotes}

${ }^{\mathrm{i}}$ We thank a reviewer for pointing this out.

ii We thank two reviewers for clarifying the role of HABs in amplifying the preference heterogeneity.

iii We thank a reviewer for making this point.

iv We thank a reviewer for pointing this out.

${ }^{\mathrm{v}}$ We thank a reviewer for suggesting to provide more details on the ecological model and its linkage with the policy scenarios.

vi The typical walleye catch rate in Lake Erie is estimated by Ohio Department of Natural Resources to be about 2.2 hours of fishing for one fish per person for the typical angler.

vii We thank a reviewer for this suggestion.

viii We thank a reviewer for making this point.

ix We thank two reviewers for suggesting the re-weighting to get a more representative average welfare measure.

${ }^{\mathrm{x}}$ We thank a reviewer for suggesting reporting aggregate consumer surplus as opposed to aggregate revenue of Ohio’s sport fishing industry. 